Portland State University

PDXScholar

TREC Final Reports

Transportation Research and Education Center

(TREC)

$10-2013$

\title{
Commute-Friendly, Gas-Electric Hybrid Vehicle Testing
}

James Long

Oregon Institute of Technology

Hugh Currin

Oregon Institute of Technology

Xin Wang

Oregon Institute of Technology

Follow this and additional works at: https://pdxscholar.library.pdx.edu/trec_reports

Part of the Environmental Sciences Commons, and the Transportation Commons Let us know how access to this document benefits you.

\section{Recommended Citation}

Long, J., Currin, H., Wang, X., Commute-Friendly Gas-Electric Hybrid Vehicle Testing. OTREC-RR-13-11. Portland, OR: Transportation Research and Education Center (TREC), 2013. https://doi.org/10.15760/ trec.64

This Report is brought to you for free and open access. It has been accepted for inclusion in TREC Final Reports by an authorized administrator of PDXScholar. Please contact us if we can make this document more accessible: pdxscholar@pdx.edu. 


\section{SIOTREC}

FINAL REPORT

\section{Commute-Friendly, Gas-Electric Hybrid Vehicle Testing}

\section{OTREC-RR-497}

October 2013 



\title{
COMMUTE-FRIENDLY, GAS-ELECTRIC HYBRID VEHICLE TESTING
}

\author{
Final Report
}

\section{OTREC-RR-497}

\author{
by \\ Prof. James N. Long \\ Prof. Hugh Currin, Ph.D. \\ Prof. Xin Wang, Ph. D. \\ Oregon Institute of Technology \\ for \\ Oregon Transportation Research \\ and Education Consortium (OTREC) \\ P.O. Box 751 \\ Portland, OR 97207

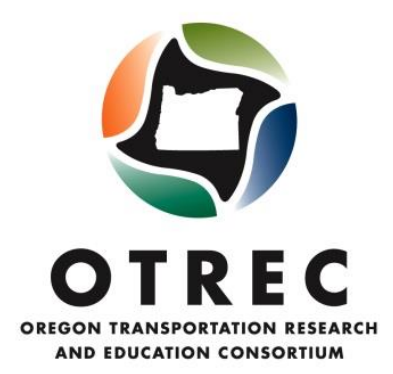

October 2013 



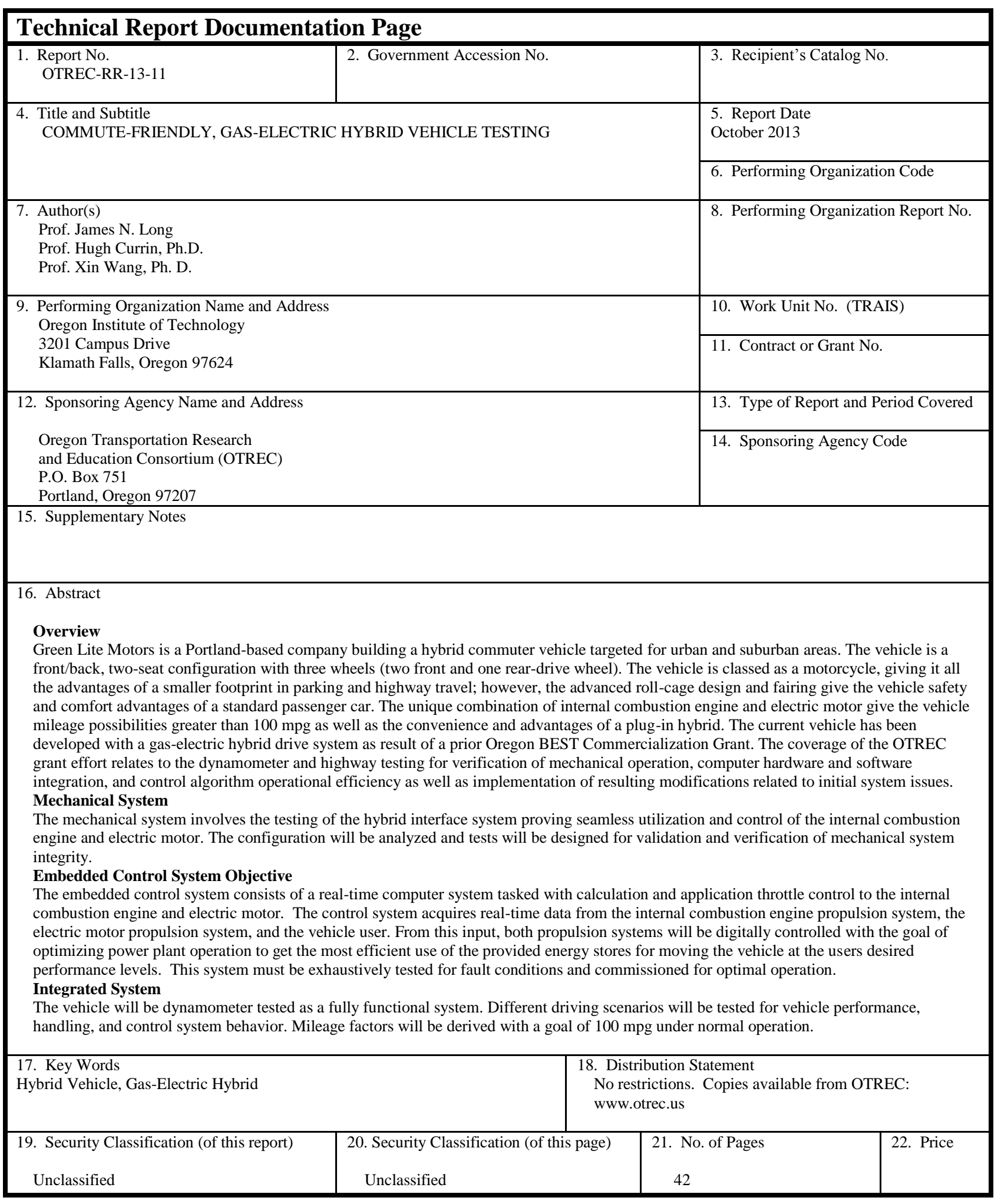




\section{ACKNOWLEDGEMENTS}

The principal investigators of this grant would like to recognize the help and support given by OTREC and affiliates. We would especially like to thank Hau Hagedorn and Carol Wallace for help in report preparation, budget management and timeline maintenance. We would also like to recognize the work put into the project by Tim Miller, CEO of Green Lite Motors, and Bob Simpson, CEO of EV Drive, for their help and guidance in the construction and troubleshooting of the various components used in vehicle construction.

\section{DISCLAIMER}

The contents of this report reflect the views of the authors, who are solely responsible for the facts and the accuracy of the material and information presented herein. This document is disseminated under the sponsorship of the U.S. Department of Transportation University Transportation Centers Program, Oregon Transportation Research and Education Consortium, Oregon Institute of Technology and Green Lite Motors, Inc. in the interest of information exchange. The U.S. Government, Oregon Transportation Research and Education Consortium, Oregon Institute of Technology and Green Lite Motors, Inc. assume no liability for the contents or use thereof. The contents do not necessarily reflect the official views of the U.S. Government Oregon Transportation Research and Education Consortium, Oregon Institute of Technology or Green Lite Motors, Inc. This report does not constitute a standard, specification, or regulation. 


\section{TABLE OF CONTENTS}

EXECUTIVE SUMMARY ............................................................................................................... 1

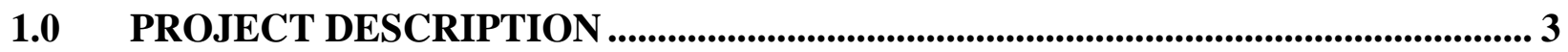

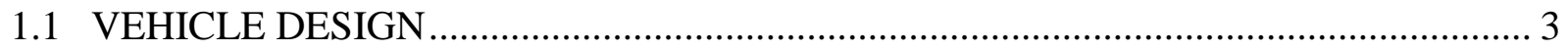

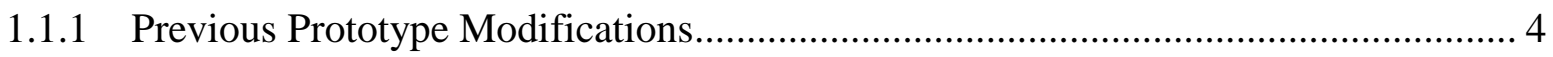

1.1.2 Next-generation Prototype Design...................................................................... 5

1.1.2.1 Mechanical Systems .................................................................................... 5

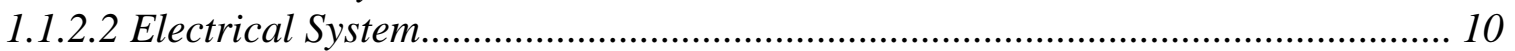

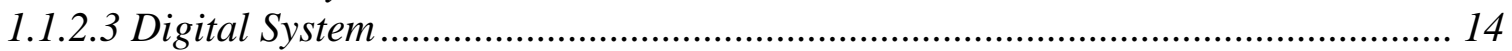

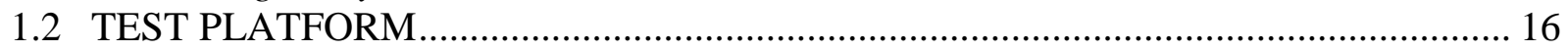

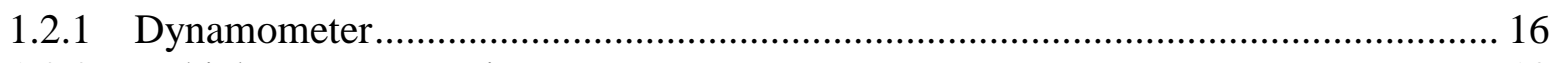

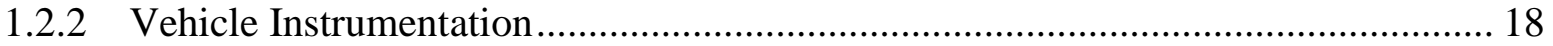

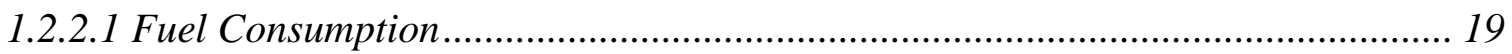

1.2.2.2 Electrical Power Consumption …………......................................................... 20

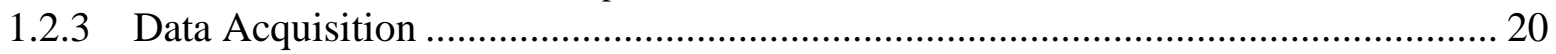

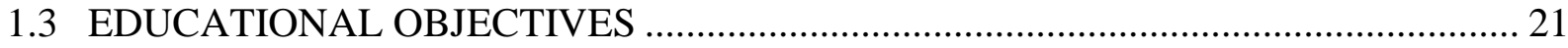

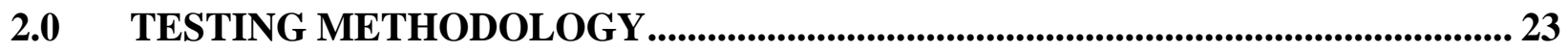

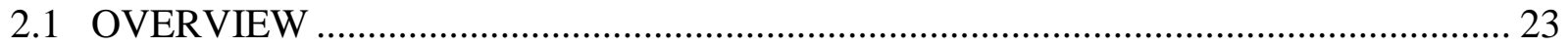

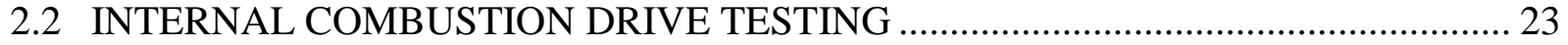

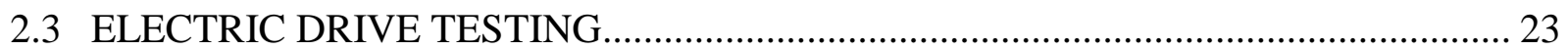

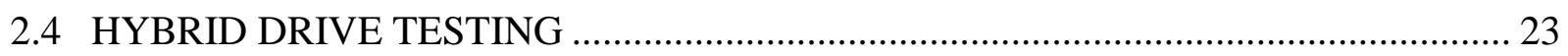

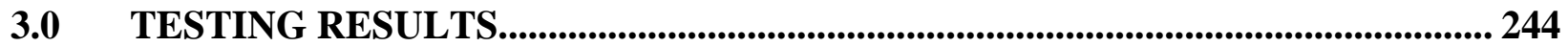

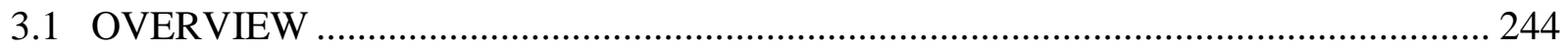

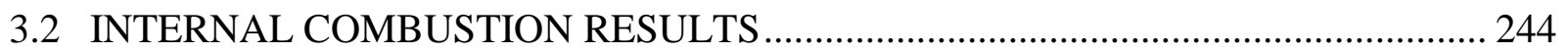

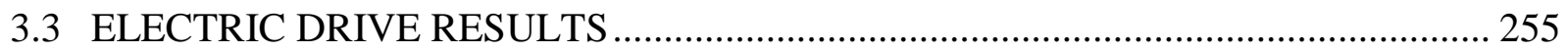

3.4 HYBRID DRIVE RESULTS ................................................................................ 29

4.0 ANALYSIS .................................................................................................................... 300

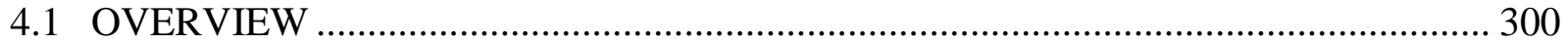

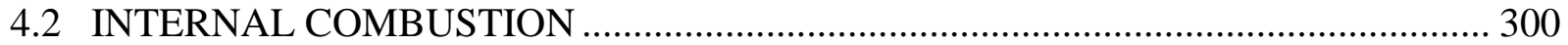

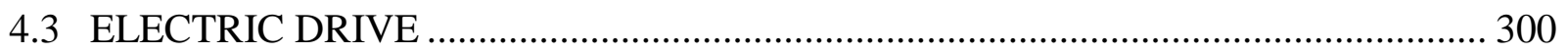

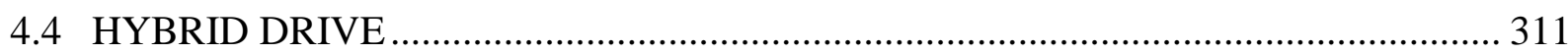

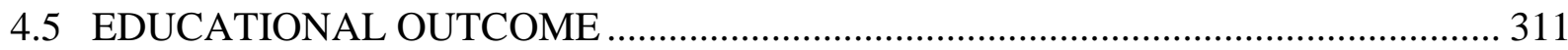

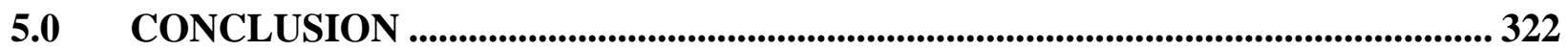

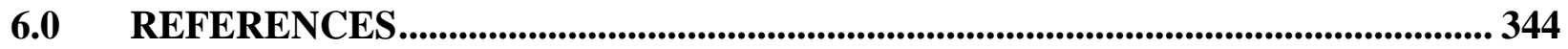

\section{LIST OF TABLES}

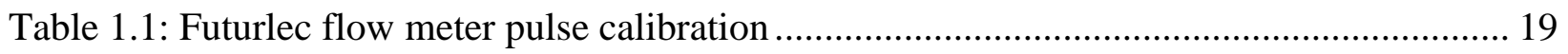

Table 3.1: Gasoline drive system testing results - Test 1...................................................... 255

Table 3.2: Gasoline drive system testing results - Test 2 …………………………................... 255

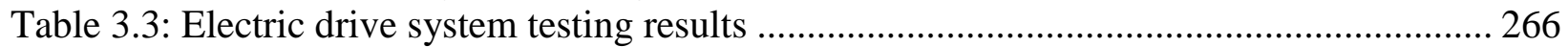

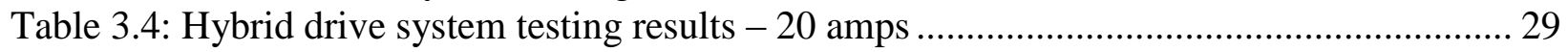




\section{LIST OF FIGURES}

Figure 1.1 - Green Lite first-generation prototype .......................................................... 3

Figure 1.2 - Green Lite concept drawing of the second-generation vehicle ............................... 4

Figure 1.3 - CAD drawing of left swing arm with sprag clutch....................................... 6

Figure 1.4 - Picture of left swing arm with idler gears .............................................. 7

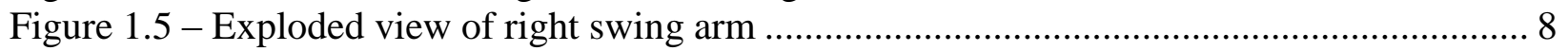

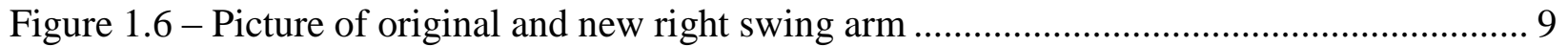

Figure 1.7 - Solid model of electric drive, sectioned ....................................................... 10

Figure 1.8 - Curtis 1238 controller............................................................................. 11

Figure 1.9 - AC 15 electric motor .......................................................................... 11

Figure 1.10 - One side of the Green Lite Motors battery bank (in the middle of a rebuild cycle)

Figure 1.11 - 10AH Headway Cell............................................................................. 12

Figure 1.12 - Manzanita Micro SOC Head .......................................................................... 13

Figure 1.13 - Green Lite Motors next-generation electric system block diagram .................... 13

Figure 1.14 - Quick Charge battery charger................................................................. 14

Figure 1.15 - The digital control system, peripheral definition, and wiring connections ........... 16 Figure 1.16 - The dynamometer with the Green Lite vehicle in the OIT dynamometer test room

Figure 1.17 - Fuel-flow sensor used in the testing setup..................................................... 19

Figure 1.18 - AcuAMP DCT200 Hall Effect current transducer used for power consumption data

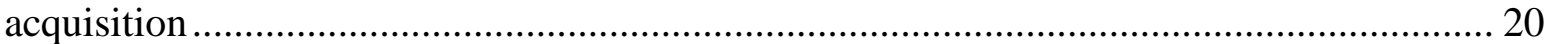

Figure 1.19 - NI USB 6009 PC DAQ Module .............................................................. 21

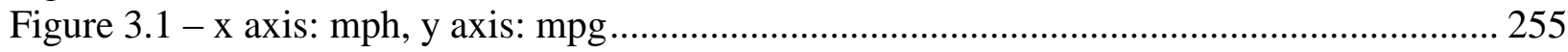

Figure 3.2 - Electric drive system range ( $\mathrm{x}$ - speed in mph vs. $\mathrm{y}$ - range in miles) ................. 266

Figure 3.3 - Electric drive amp consumption ( $\mathrm{x}$ - speed in mph vs. y instantaneous amps) ..... 277

Figure 3.4 - Electric drive amp consumption ( $\mathrm{x}$ - speed in mph vs. y instantaneous amps) ..... 277 Figure 3.5 - The manufacturing defect discovered upon disassembly of one of the battery banks 


\section{EXECUTIVE SUMMARY}

Green Lite Motors has developed a small, three-wheeled, gas-electric hybrid vehicle based on a platform of a Suzuki Bergman scooter. The target market for this vehicle is urban commute zones where large numbers of individuals migrate from suburban homes to city-based professions. Under normal commute circumstances, traffic and parking congestion contribute to loss of worker productivity, increase in air pollutants and unnecessary waste of gasoline. The introduction of the Green Lite Motors vehicle into this market could have a large impact due to the vehicle's high mileage and small footprint. The manufacturing plan is to modify an existing scooter platform to create an enhanced platform with better mileage and more commuter appeal. The use of existing technology decreases engineering overhead while leveraging the design expertise of a large vehicle engineering team.

The first prototype was developed based on a Suzuki Bergman 450 as the platform vehicle. This vehicle proved the engineering concept and pushed the creation of a second vehicle. The second prototype was based on a larger platform, the Suzuki Bergman 650. This work was done under an Oregon BEST Commercialization Grant (Long, Currin \& Wang, 2012). The hybridization of the 650 required a completely new engineering solution, thus newer battery technology was adapted as well a complete re-engineering of the hybrid drive system.

The project outcome detailed in this report encompasses the testing and troubleshooting of this second prototype. To perform the tests, a small dynamometer was funded and purchased through the grant. The dynamometer was used to provide laboratory-based road loads for the vehicle while also gathering some basic information on the performance of the internal combustion (IC) engine. A fuel-flow meter was also adapted to the IC drive system to get an independent measure of fuel consumption. The electric system was instrumented as an independent drive system for measurement of coulomb consumption in an attempt to measure miles per watt/hour.

Problems with the LiFePO4 battery system plagued the operation of the electric drive system, eventually bringing an early end to the vehicle testing. This was due to an expenditure of funds in the repairing of the LiFePO4 battery banks. In light of the battery issues, the vehicle's mechanical and electrical systems were tested and several issues were identified and corrected.

The report contains information related to:

1. Vehicle configuration

2. Test platforms and configuration

3. Educational objectives

4. Testing results

5. Final analysis 


\subsection{PROJECT DESCRIPTION}

\subsection{VEHICLE DESIGN}

Green Lite's commercialization collaboration with the Oregon Institute of Technology (OIT), funded through Oregon BEST (Long, Currin \& Wang, 2012) developed its next proof-of-concept vehicle. The first-generation vehicle was based on a smaller Suzuki Bergman platform, the Bergman 450 (Figure 1.1).

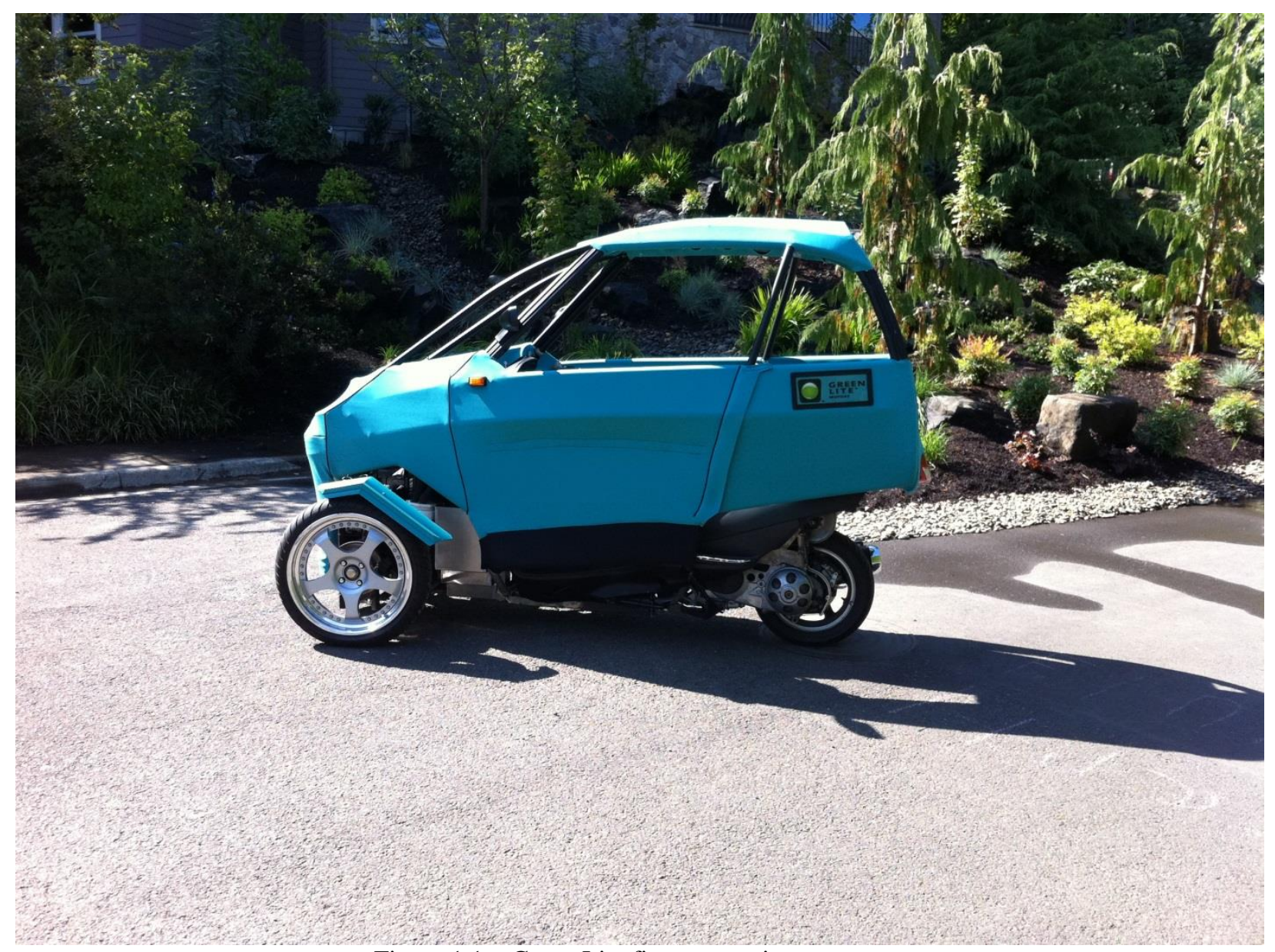

Figure 1.1 - Green Lite first-generation prototype

The next-generation prototype development goal, in the collaboration with OIT, was hybrid conversion of a larger capacity Suzuki Burgman 650 platform scooter. Once the scooter was converted, Green Lite would pursue the three-wheel lean steering and a fairing design. The target concept vehicle is an enclosed, three-wheel vehicle targeted at the commuter market (Figure 1.2). 


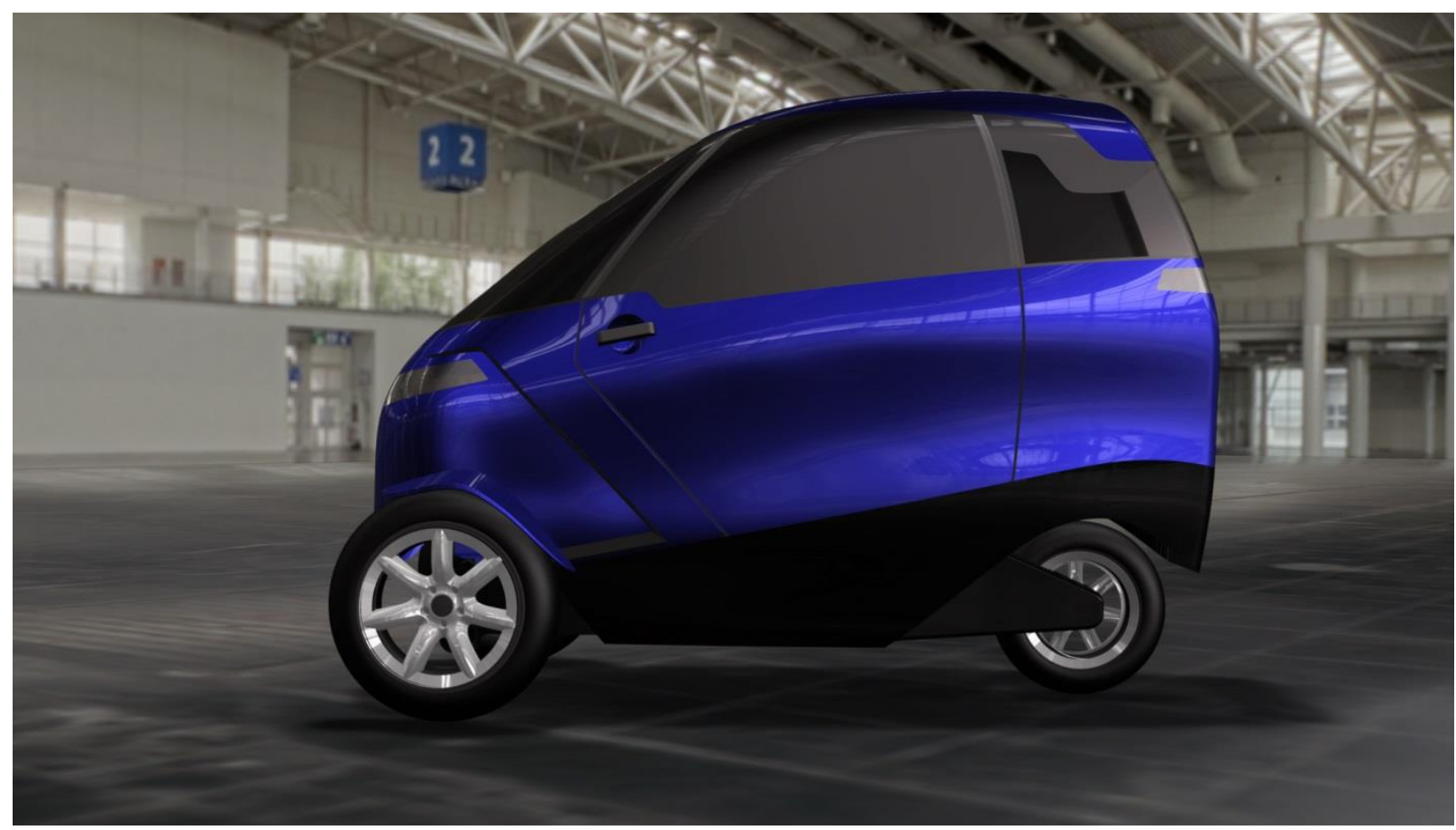

Figure 1.2 - Green Lite concept drawing of the second-generation vehicle

Green Lite's collaboration with OIT was to develop its next proof-of-concept vehicle. Green Lite's goals included a larger capacity scooter, specifically a Suzuki Burgman 650. Green Lite had previously pursued a concept vehicle using a Suzuki 450 scooter. The goal of the collaboration with OIT was to convert the Burgman 650 to hybrid operation. After scooter conversion, Green Lite would pursue the three-wheel lean steering and a fairing design.

\subsubsection{Previous Prototype Modifications}

The first prototype was studied and a series of target features were identified for hybridization of the Burgman 650.

1. Add a freewheeling mechanism for the internal combustion (IC) drive train.

2. Add an electric motor for a gas/electric hybrid.

3. Adapt an AC motor and a Curtis controller for future use of braking regeneration.

4. Introduce single throttle operation through servo movement and analog signal generation.

5. Introduce rudimentary battery charge management for use in power control.

6. Update the battery pack to utilize LiFePO4 battery chemistry.

7. Add a single board computer control system for hybrid drive function.

The first was not attempted on the previous proof-of-concept vehicle. It was found that if a freewheeling mechanism wasn't included, the IC engine acts like a compressor during coasting, 
dissipating energy. This isn't a major problem with a stock scooter; the compression on coasting only hurts efficiency slightly. However, with a hybrid electric motor, the IC motor's drag is a larger problem since back driving the IC motor with the electric motor is a major loss of efficiency.

In the first proof-of-concept vehicle, the electric motor was mounted to the rear swing arm. This added unsprung weight wasn't optimum. Unsprung weight promotes fatigue failures or added structural weight. Also, there was no reasonable way to mount an electric motor, of the size needed, on the Burgman 650's swing arm. Thus a design was needed to move the motor to the scooter's frame.

The first proof-of-concept vehicle had two throttles, one for the IC engine and one for the electric motor. This made operation and demonstration difficult. A major goal of the controls was to incorporate both throttles into a single control.

The electric drive system was also updated to utilize newer, more power-dense LiFePO4 battery chemistry. This proves to have a better watt-per-pound rating; however, management of the charge/discharge curve for these batteries can be problematic. The AC system was added as an enhancement over the first-generation prototype for utilization of regenerative braking in hope of squeezing more performance out of the electric system. The Curtis controller provides good functionality for regenerative and $\mathrm{AC}$ motor control; however, the level of customization for this controller made it somewhat difficult to initially configure. The Curtis controller allows for use of an analog signal for control of the throttle from any variable voltage source.

The previous prototype did not have a unified hybrid drive system. To introduce this, a single board computer was added to take in the desired performance of the driver (economy or power); the type of trip the driver was making (city high-frequency start and stop or rural continuous cruising); the current charge gauge of the battery bank; and the power request from the throttle. The control algorithm then calculated the percentage of power from both the IC and the electric motor.

\subsubsection{Next-generation Prototype Design}

In making the mechanical modifications to the Burgman 650, it was found that the bike is a very well-designed and integrated scooter. These are good qualities for a scooter but it makes major modifications very difficult. Mechanical and electrical systems had to be added for full hybrid vehicle implementation. The space and power efficiency built into the original Burgman 650 made additions a challenging task.

\subsubsection{Mechanical Systems}

Several configurations were considered for adding a freewheeling mechanism. A hard look was given to converting the centrifugal clutch of manual/electric operation. Also, consideration was given to putting a sprag clutch (freewheel mechanism) inside the 
clutch housing. Both seemed difficult and likely to lead to a less reliable system. The final drive on this bike is a series of idler gears rather than a chain. The idlers made adding a freewheel more difficult than if a chain were used. However, it was the surest way to configure the new system.

One idler gear was removed from the series of idlers in the left swing arm. Shafts from the adjacent gears were extended outside the swing arm case. Connecting these two shafts with a chain drive gave an equivalent mechanical system. On one shaft, a sprag clutch (freewheeling mechanism) was included. Thus power could flow from the IC engine to the rear wheel, but the rear wheel could not drive the IC engine backwards. The idler gears turned out to be non-standard. Figure 1.3 shows the final configuration.

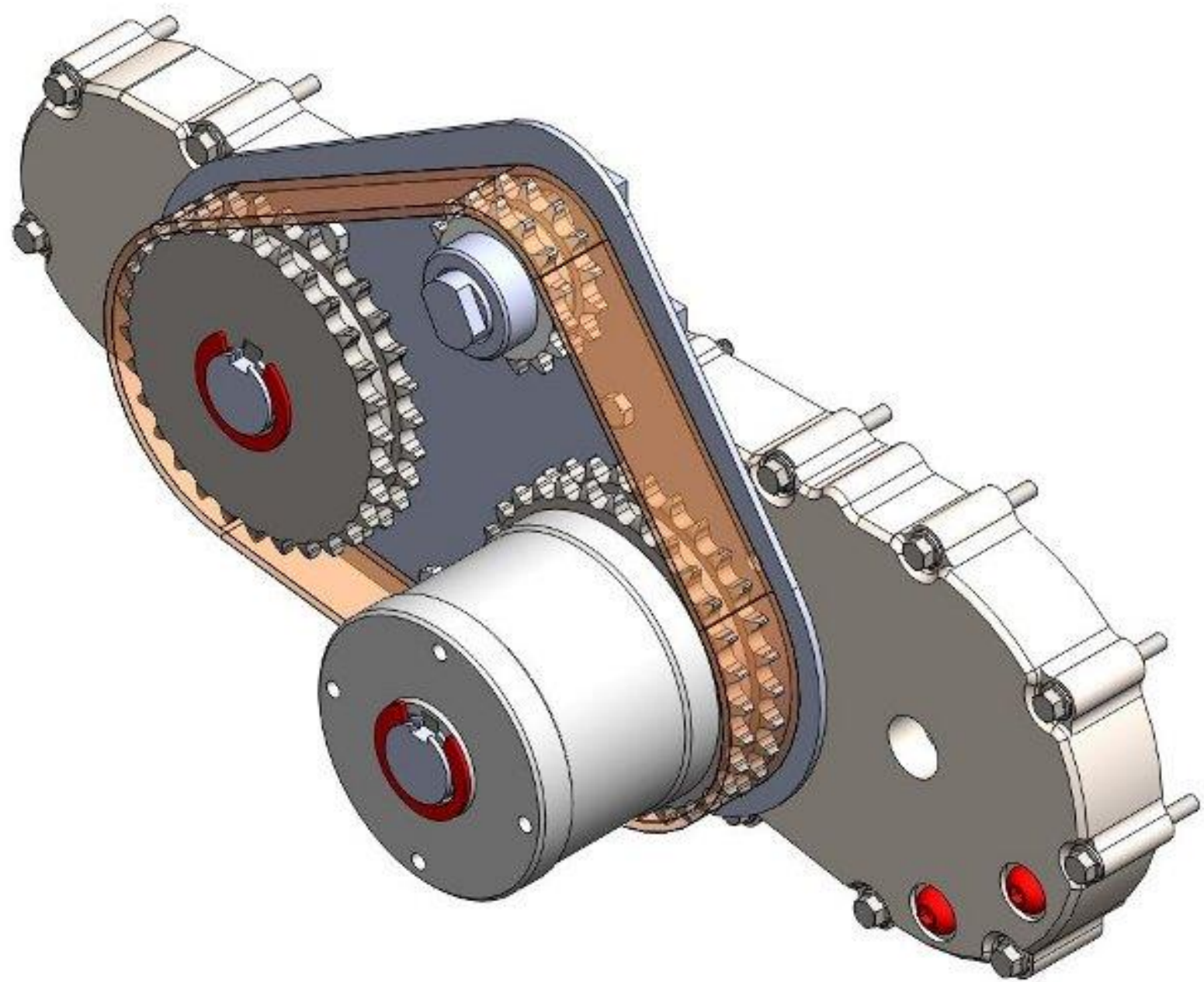

Figure 1.3 - CAD drawing of left swing arm with sprag clutch

The stock Burgman idler gears needed to be modified rather than obtaining new stock gears. However, the idler gears are well optimized. They have thin webs from the hub to the gear teeth and a radially thin hub, as shown in Figure 1.4. This is good for their use as idlers, but difficult to add a shaft to. The thin hub doesn't leave enough material for a keyway and also hardened. In addition, the thin hub caused problems with a press or shrink fit. Its lack of material limits the pressure applied to an interference fit. It was 
decided to use the heaviest shrink fit that was thought workable. The shaft was cooled in dry ice and the gear heated to a temperature thought to be below its tempering temperature. The shrink fit is thought to be adequate for the torques present but with little margin for error.

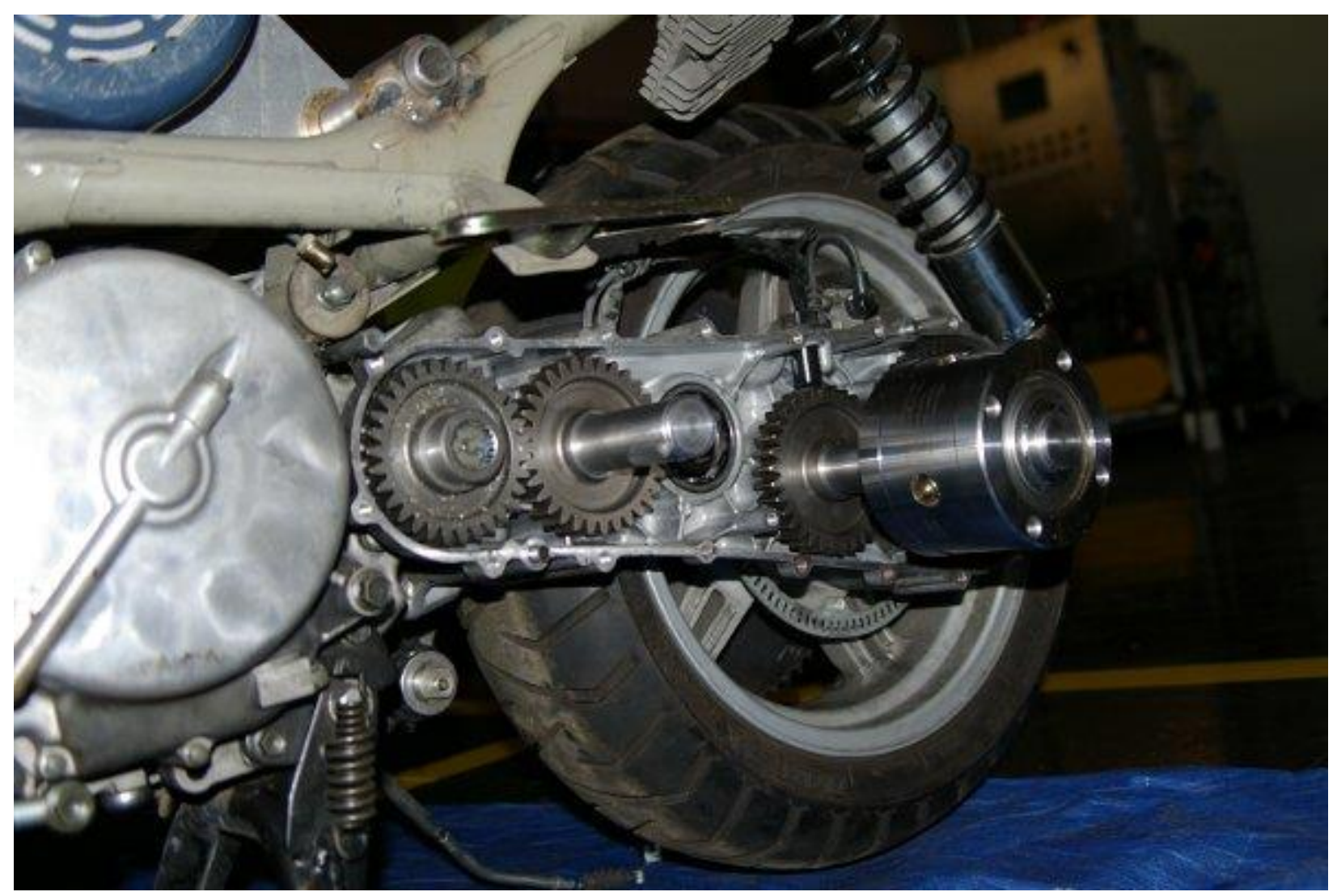

Figure 1.4 - Picture of left swing arm with idler gears

In addition to issues with the idler gear/clutch modification, the electric motor was difficult to integrate. Green Lite wanted to retain the option to implement regeneration. For this to be effective, energy needs to be transmitted to and from the rear wheel. By far the most effective transmission element for the electric motor is a flexible transmission element, a belt or chain. For regeneration, a flexible element will have tension on both sides and no "slack" side. Thus, use of a spring tensioner was not possible, and the center distance between sprockets or sheaves needed to remain constant. The only way to maintain a constant center distance was to place one sprocket/sheave of each stage on the swing arm pivot axis. This was not feasible on the left, idler side of the swing arm, so modification to the right swing arm was pursued.

To keep the swing arm width as narrow as feasible, chains were selected for the transition through the swing arm pivot. To mount two sprockets on the swing arm axis, the swing arm had to be moved out some 3 inches. Figure 1.5 shows an exploded view of the new swing arm. A number of plates were used to space the swing arm further outboard, and 
the outer steel structure made as a weldment. Figure 1.6 shows a picture of the new swing arm along with the original.

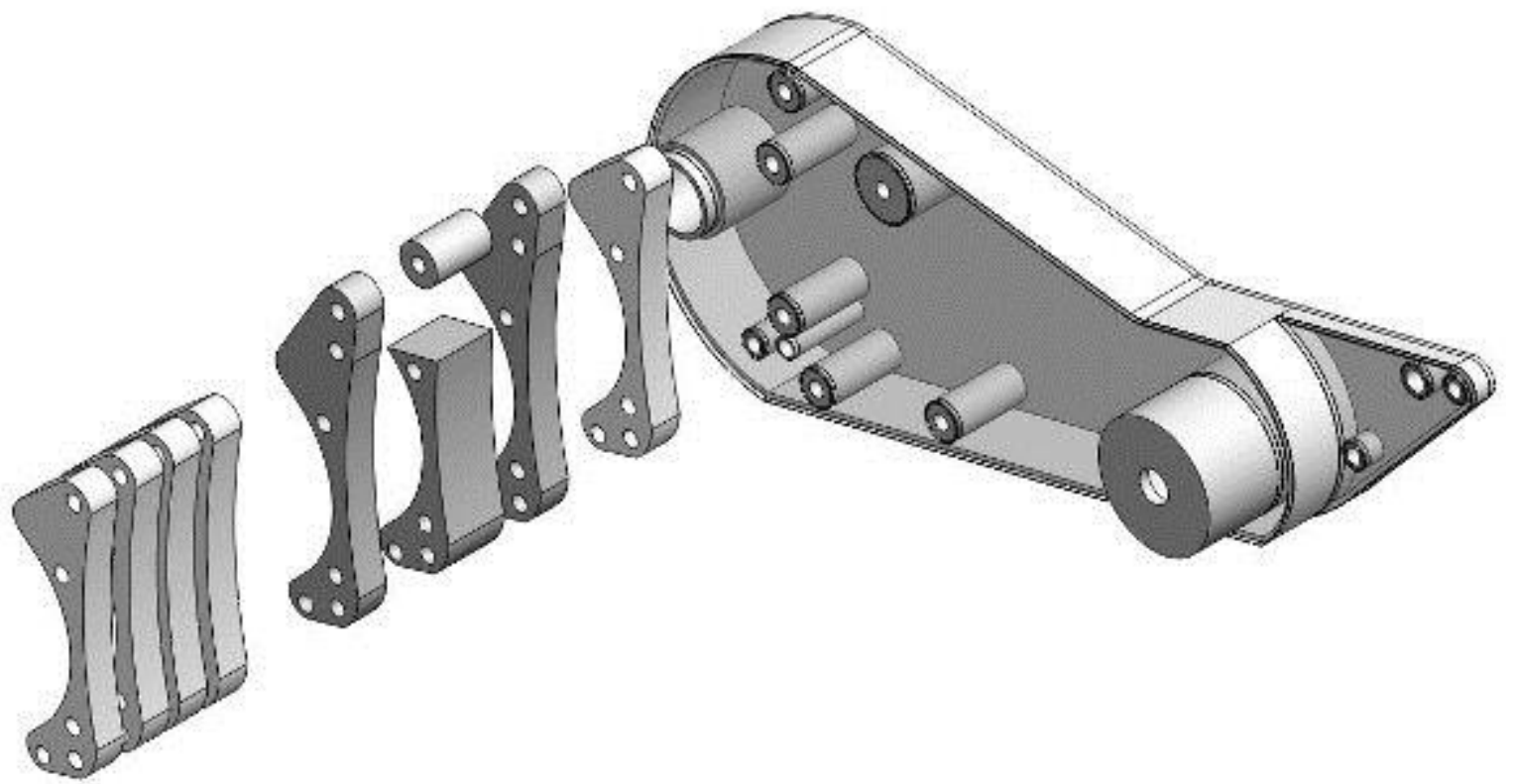

Figure 1.5 - Exploded view of right swing arm 


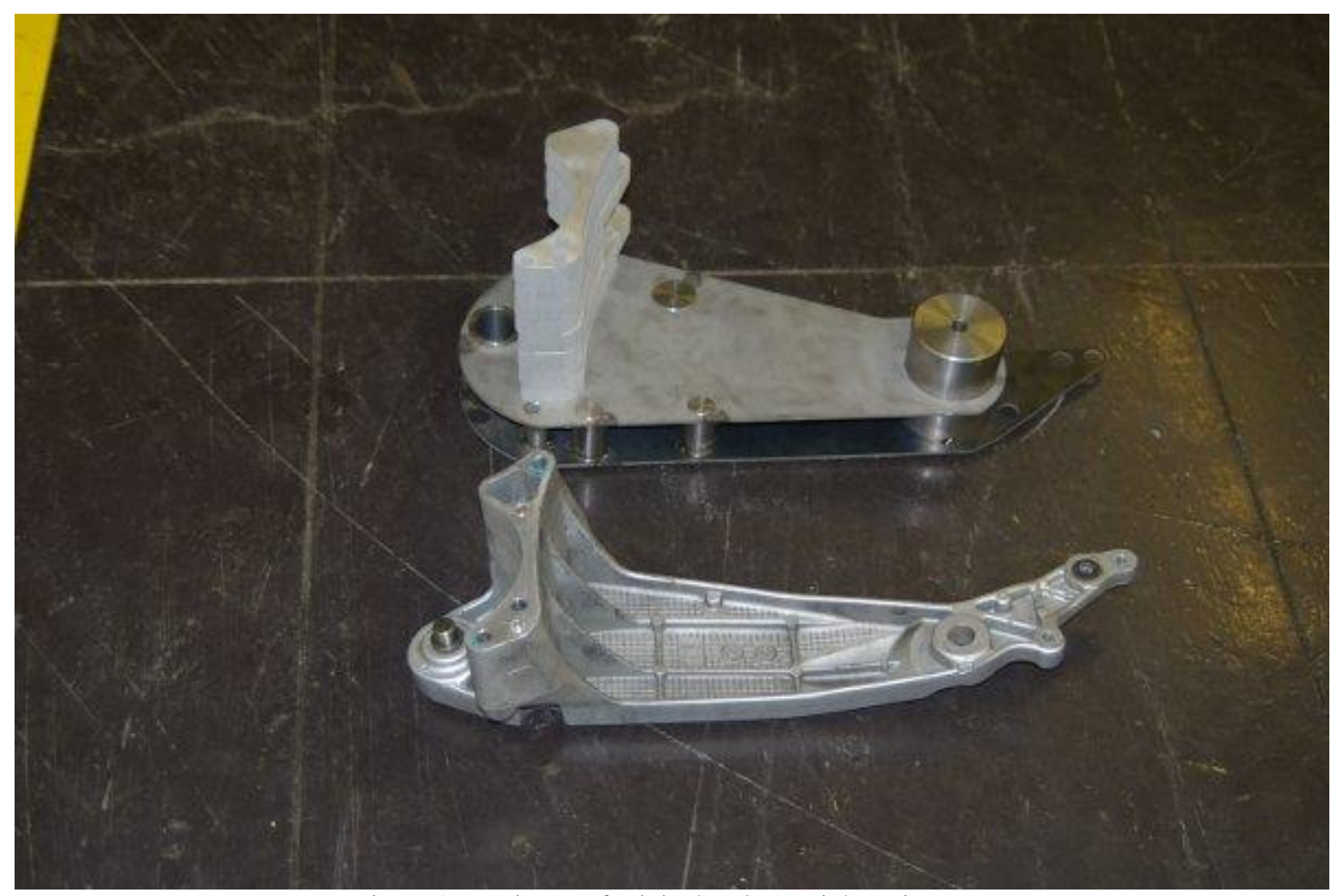

Figure 1.6 - Picture of original and new right swing arm

The initial concept used a three-stage electric drive. A chain transmitted power from the rear wheel sprocket to a sprocket at the swing arm axis. Another stage ran from a second sprocket on the swing arm axis to an intermediate shaft under the seat. A timing belt stage connected this intermediate shaft to the electric motor. The removal of a storage bin and gas tank from under the seat in the original scooter configuration made room for the electric motor and a smaller gas tank. Figure 1.7 shows the final configuration of the electric drive; however, the upper chain idler was removed, allowing a straight run to the pivot sheave. The three-stage drive was replaced with a two-stage chain setup. This simplified the system considerably, though the chains are running above recommended speed. It was thought this would function well but lead to shortened chain life. 


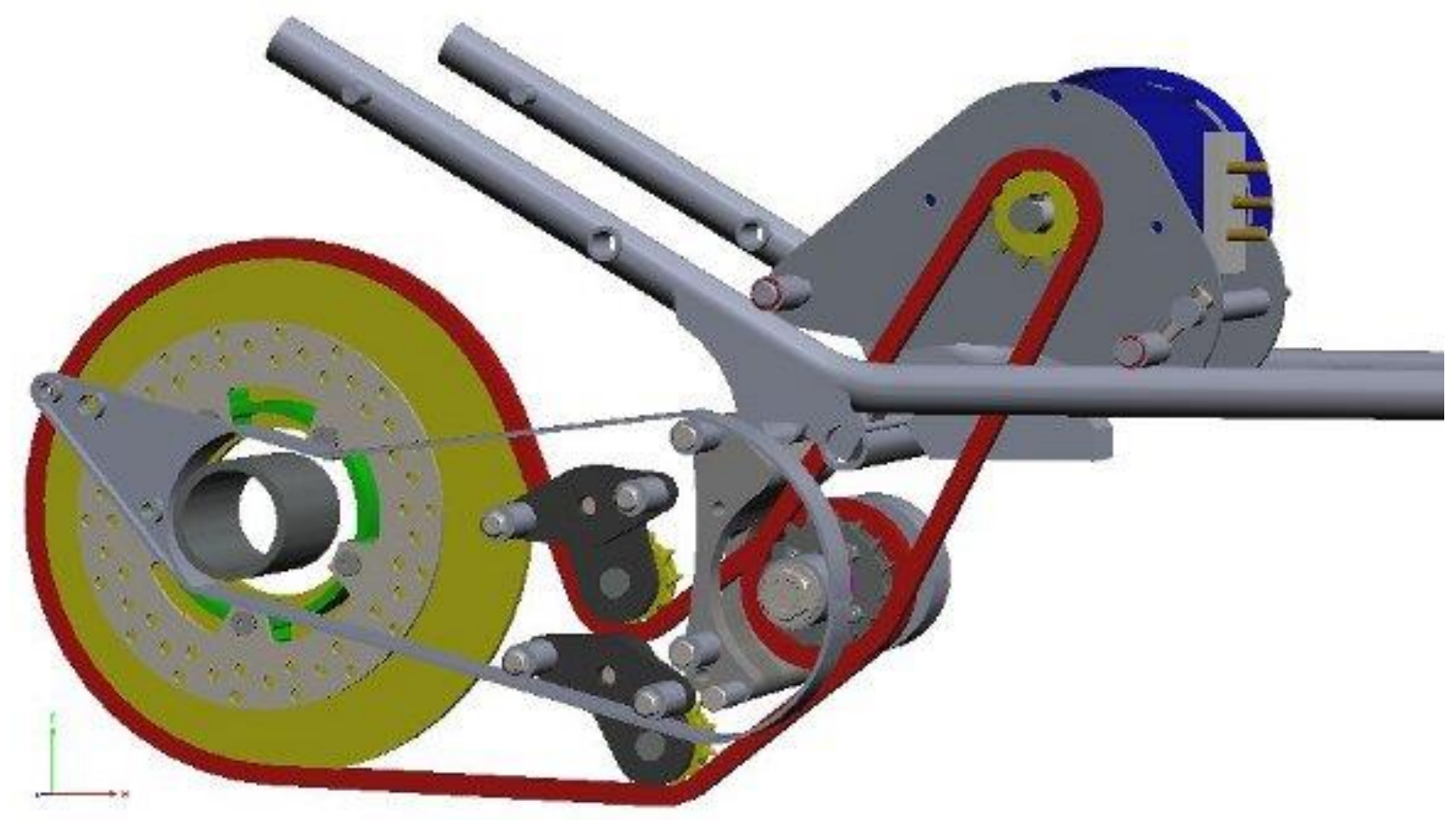

Figure 1.7 - Solid model of electric drive, sectioned

\subsubsection{Electrical System}

The electrical system encompasses a high-voltage system running at 72 volts and a lowvoltage system running at a standard 12 volts. The low-voltage system provides for service-level electronics required of the stock vehicle systems as well as the augmented power requirements of the hybrid operation control system. The high-voltage system drives the electric motor and must be monitored for charge level so battery status can be used as an input variable into the control algorithm.

The high-voltage drive system consists of a Curtis 1230 AC controller (Figure 1.8), 


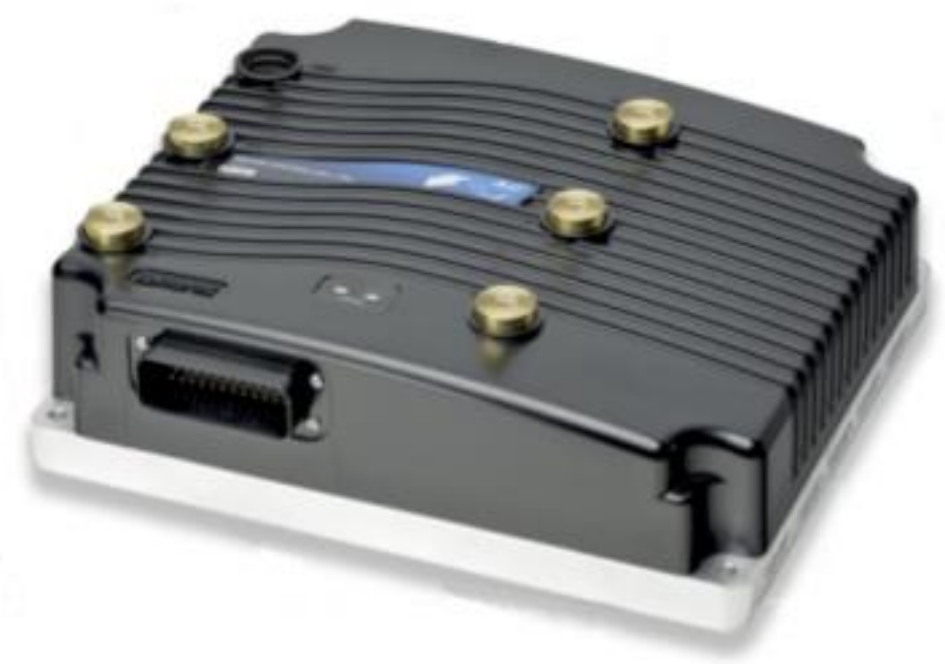

Figure 1.8 - Curtis 1238 controller

an AC 15 three-phase electric motor run at 72 volts with a peak amp draw of 500 amps, producing a peak of 40 horsepower (Figure 1.9),

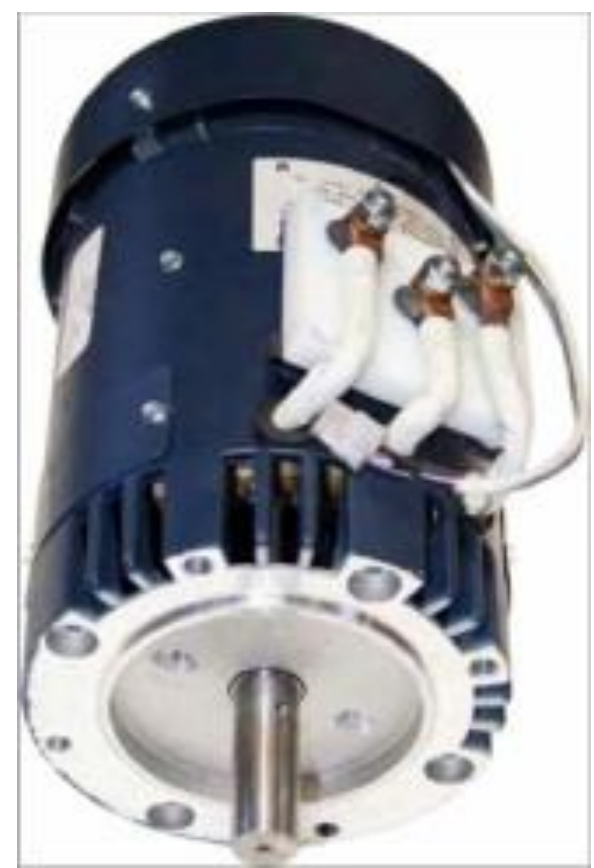

Figure 1.9 - AC 15 electric motor

and a battery bank (Figure 1.10) of LiFePO4 Headway 3.2v 10AH 38120S cells (Figure 1.11). 


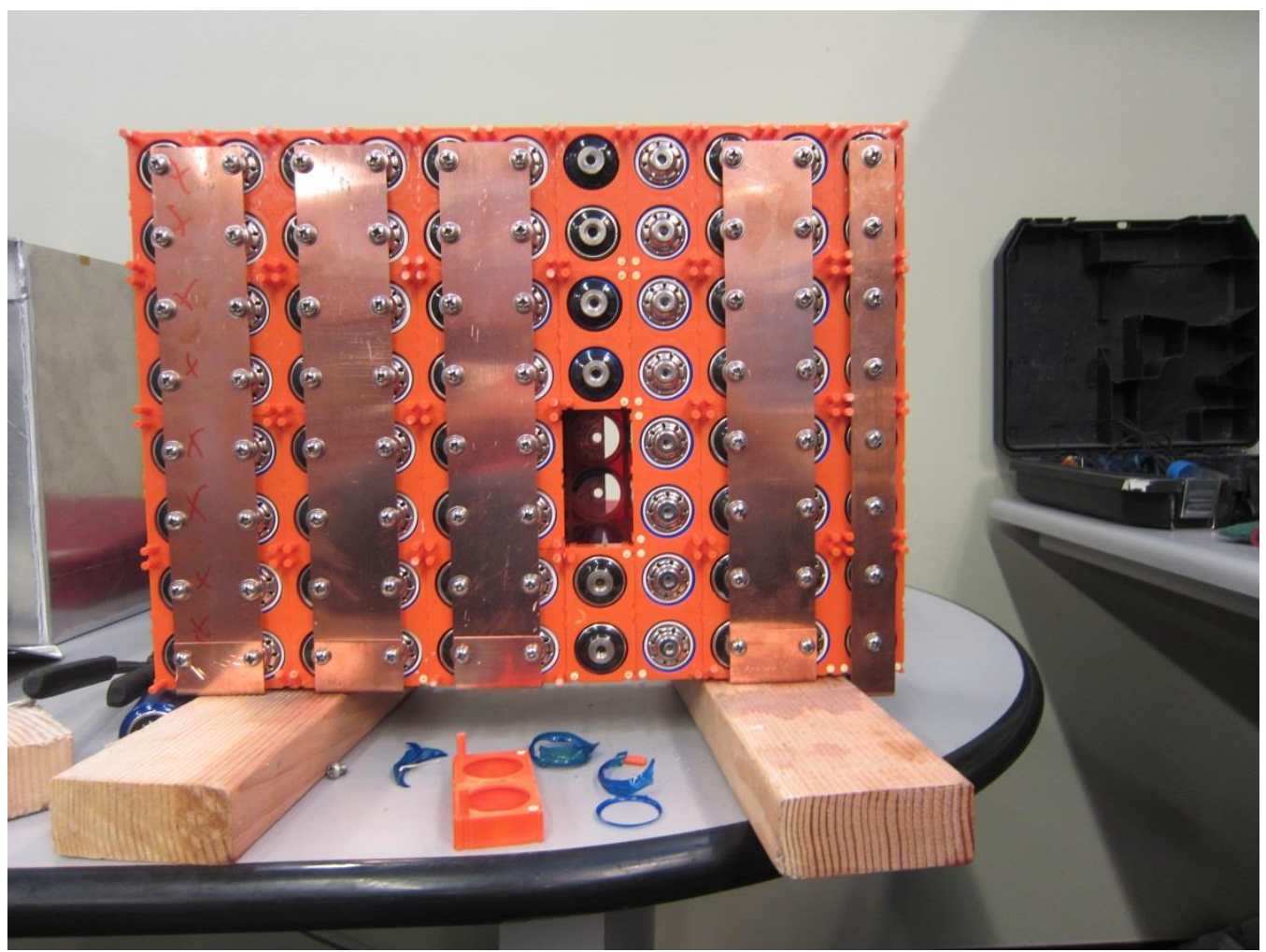

Figure 1.10 - One side of the Green Lite Motors battery bank (in the middle of a rebuild cycle)

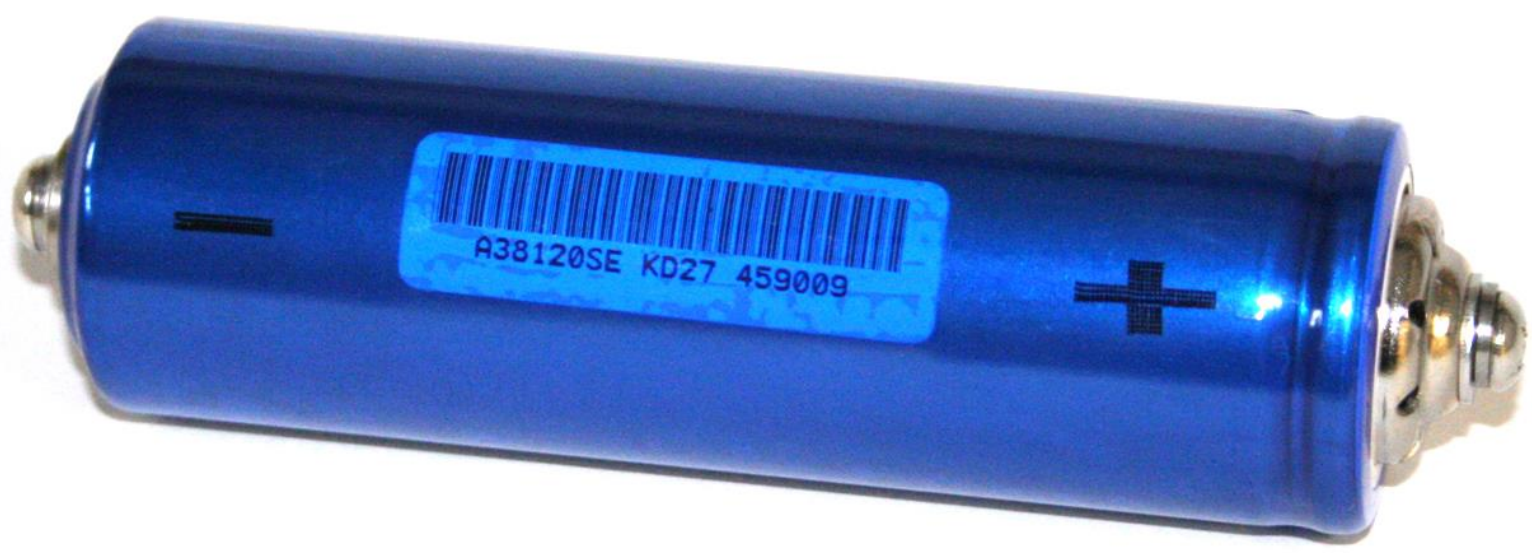

Figure 1.11 - 10AH Headway Cell

The batteries were split up into two series cases where each case contained eight cells in parallel, with 11 of the parallel strings in a series. This configuration makes a battery bank of $80 \mathrm{AH}, 70 \mathrm{~V}$ nominal, $80 \mathrm{~V}$ fully charged. To monitor the batteries' state of charge, a Manzanita Micro SOC Head (Figure 1.12) unit was deployed to monitor the current across a 750-amp shunt. 


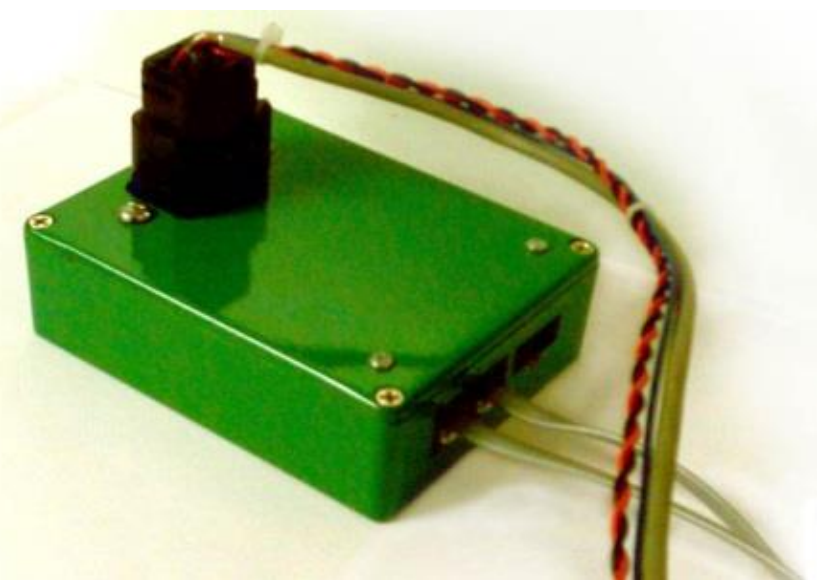

Figure 1.12 - Manzanita Micro SOC Head

The SOC Head Unit acts as a "charge gauge," keeping track of the percentage full for the battery pack. A block diagram showing the electric system and wiring is shown in Figure 1.13 .

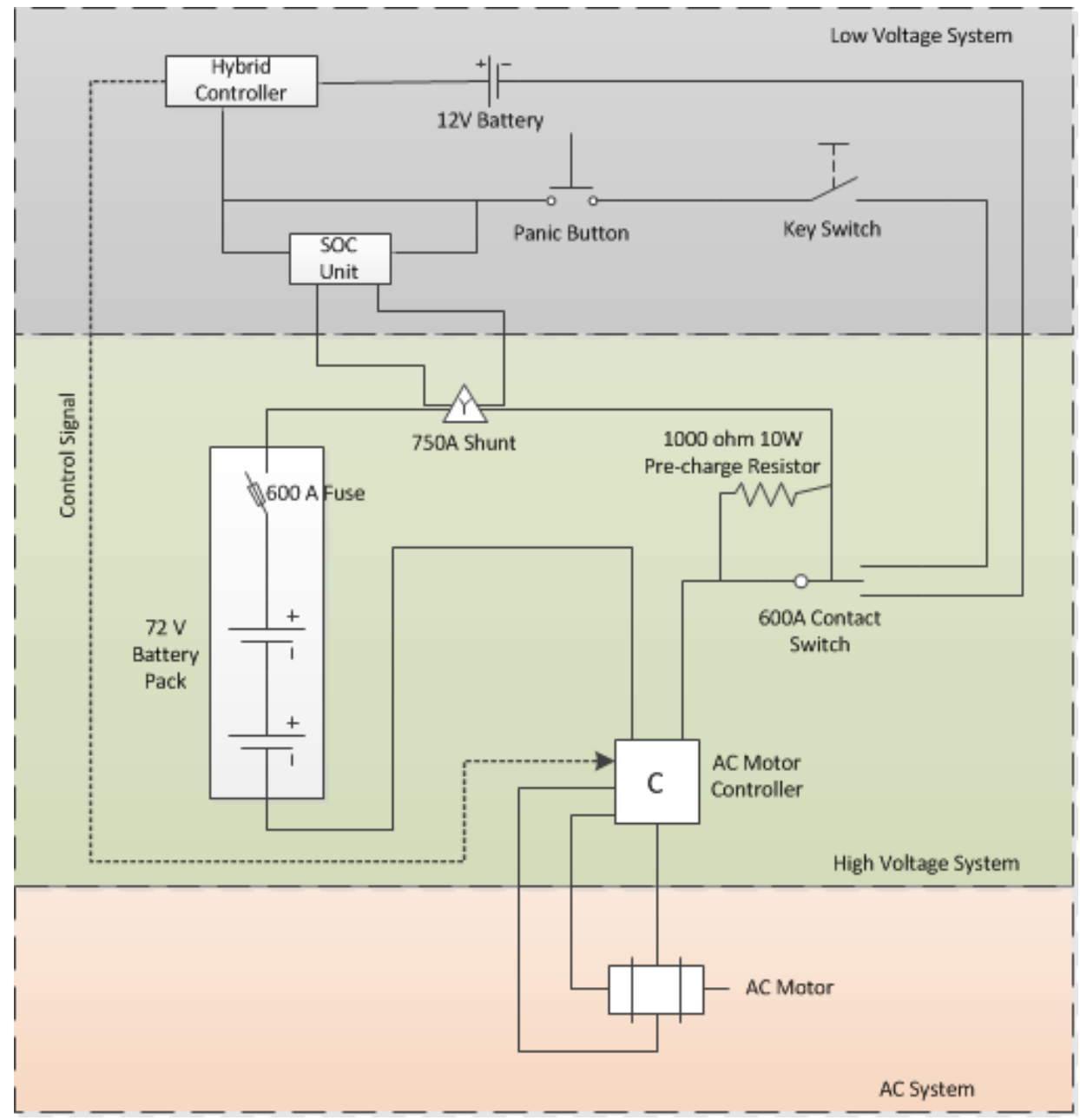

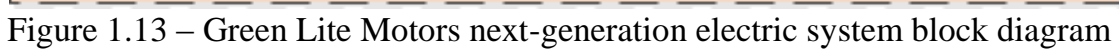


For maintenance charging of the batteries during the test cycles, a charger from Quick Charge Corporation was purchased. The charger was custom modified for the LiFePO4 battery configuration used in the vehicle. The charger is shown in Figure 1.14.

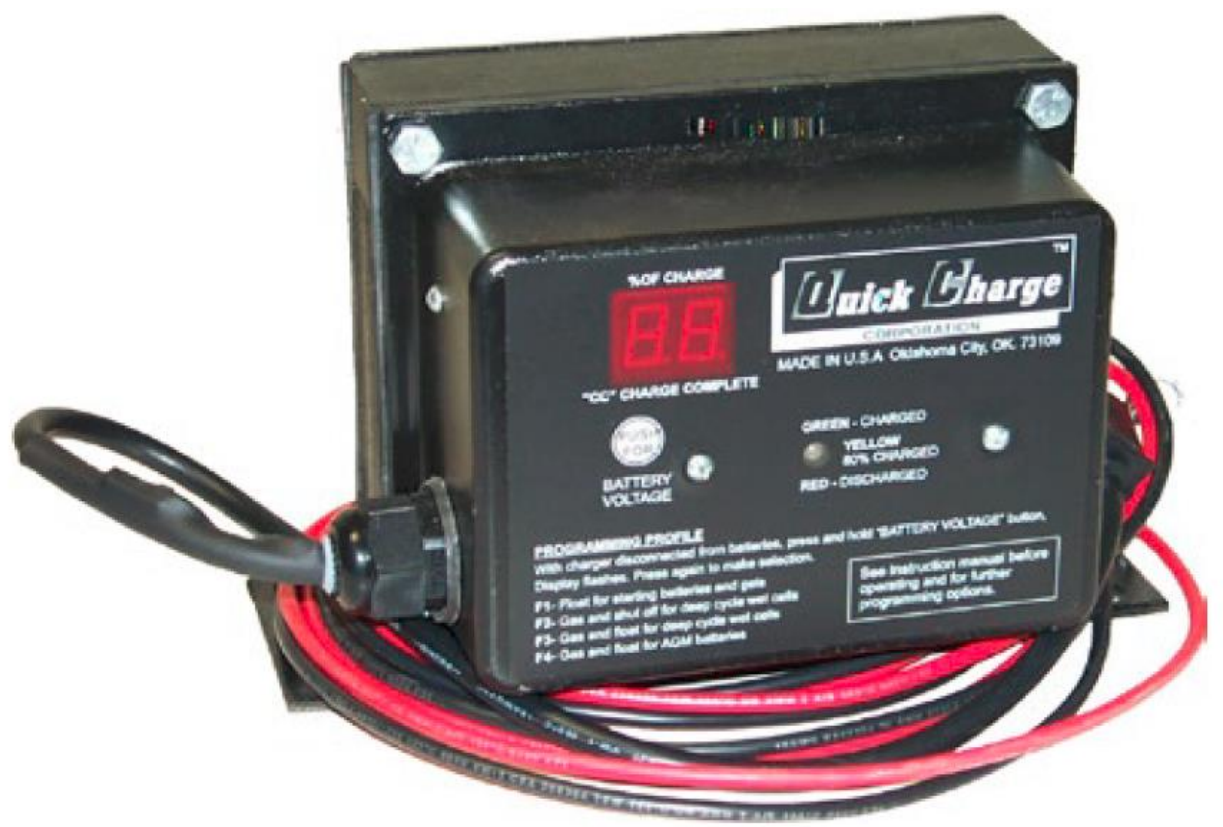

Figure 1.14 - Quick Charge battery charger

The single battery charger was chosen based on advice from our domain expert in the area of electric-vehicle power systems. Since the battery banks were new, it was not expected the individual cells would fall out of balance enough such that charging the bank as a single unit would cause damage to any individual cell. The other option would have been to purchase a battery-management system (BMS). At the time of equipment acquisition for the project, BMS charging systems were prohibitively expensive and could not be supported by the project budget. This decision proved to have detrimental effects on the overall system testing, as will be discussed in the testing results.

\subsubsection{Digital System}

The digital system contains circuits for acquiring analog control input as sensing systems and control output systems. The control computer itself is based on a Mips PIC32 microprocessor. The control system input was made simple. Four input parameters are required: 
1. Throttle potentiometer input, an analog signal from 0-5 volts capturing the driver's request for drive system power.

2. Digital user interface (UI) input for the trip type. This is a 16-bit value representing 0-100, where the trip type represents intended vehicle behavior; 0 represents a trip in a rural setting where the vehicle will be cruising with very few starts and stops.

3. Digital UI input for the driving mode. This is a 16-bit value representing 0-100; 0 represents high economy, favoring fuel efficiency over driving speed and acceleration, and 100 represents sport mode where fast acceleration is favored over fuel and battery efficiency.

4. Digital UI input for the drive engagement. This represents electric-only, IC-only and hybrid operation.

5. ASCII input from the SOC Head Unit. This is a value between $0-100 \%$ representing the current charge capacity of the battery bank.

The control algorithm uses a fuzzy logic calculation (Xin Wang, 2012) based on the throttle input, trip type, diving mode and percentage battery bank charge. The output produced is:

1. Zero- to 5-volt throttle signal to the Curtis controller for power request to the $\mathrm{AC}$ 15 electric motor.

2. Servo control to IC engine throttle servo for power request to the IC engine.

A block diagram of the digital system is shown in Figure 1.15. 


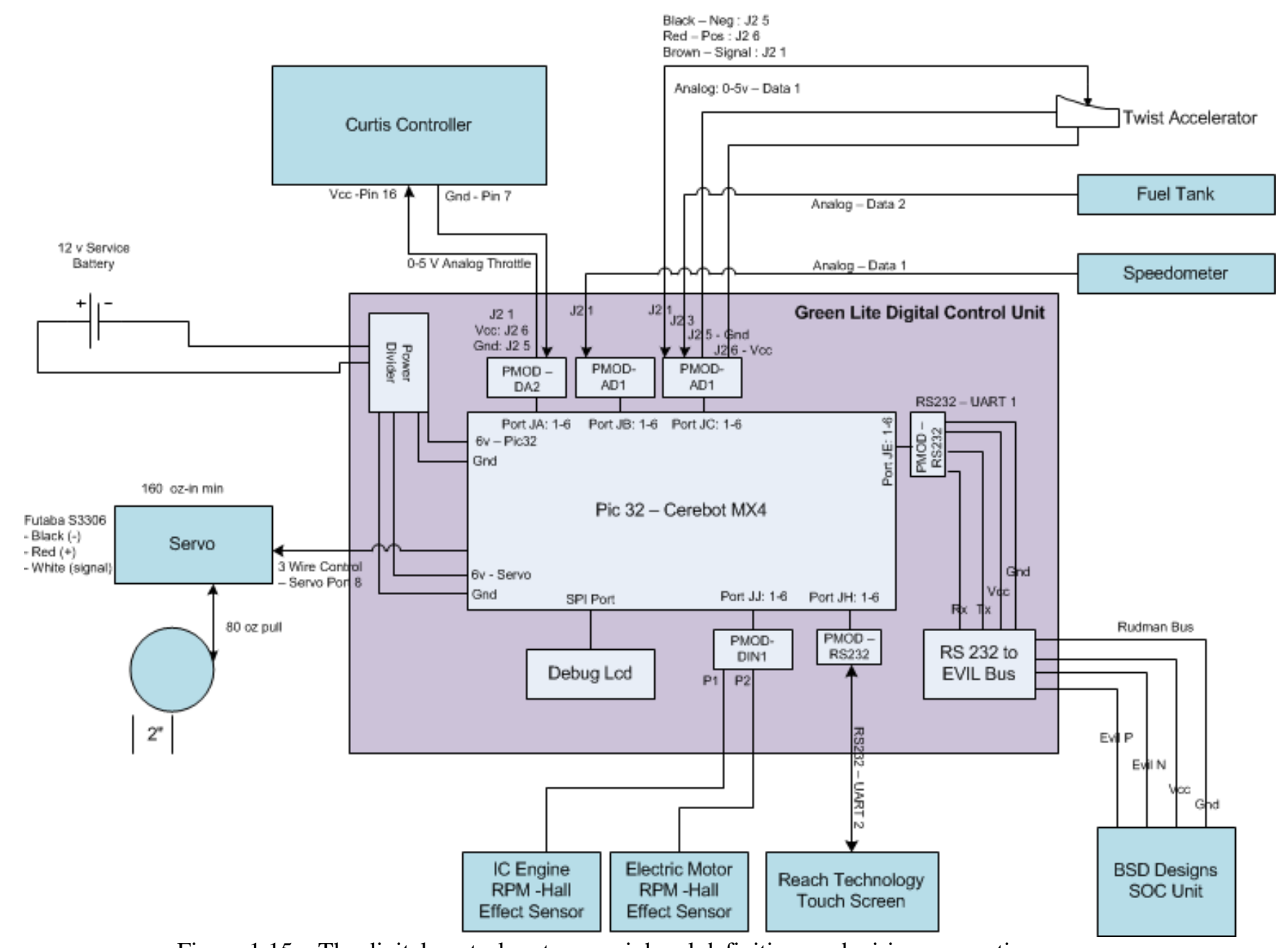

Figure 1.15 - The digital control system, peripheral definition, and wiring connections

\subsection{TEST PLATFORM}

The main objective for the grant is to test the Green Lite vehicle next-generation prototype for mechanical, electrical and hybrid operation. First and foremost is the testing and verification of the operation of each mechanical fabrication as a subsystem, then a fully functional system. The systems under consideration are the IC drive mechanism, the electric motor drive system, and the hybrid link to allow both IC and electric to run in parallel for full hybrid vehicle operation. To perform system-independent tests, a small dynamometer was deployed and the vehicle systems instrumented for data acquisition independent of the developed hybrid drive systems.

\subsubsection{Dynamometer}

The dynamometer acquired for the testing is a Motorcycle/ATV Dynamometer.

Land and Sea DYNOmite Dynamometer: 850 UTV/Formula SAE EC Dyno (Figure 1.16) 


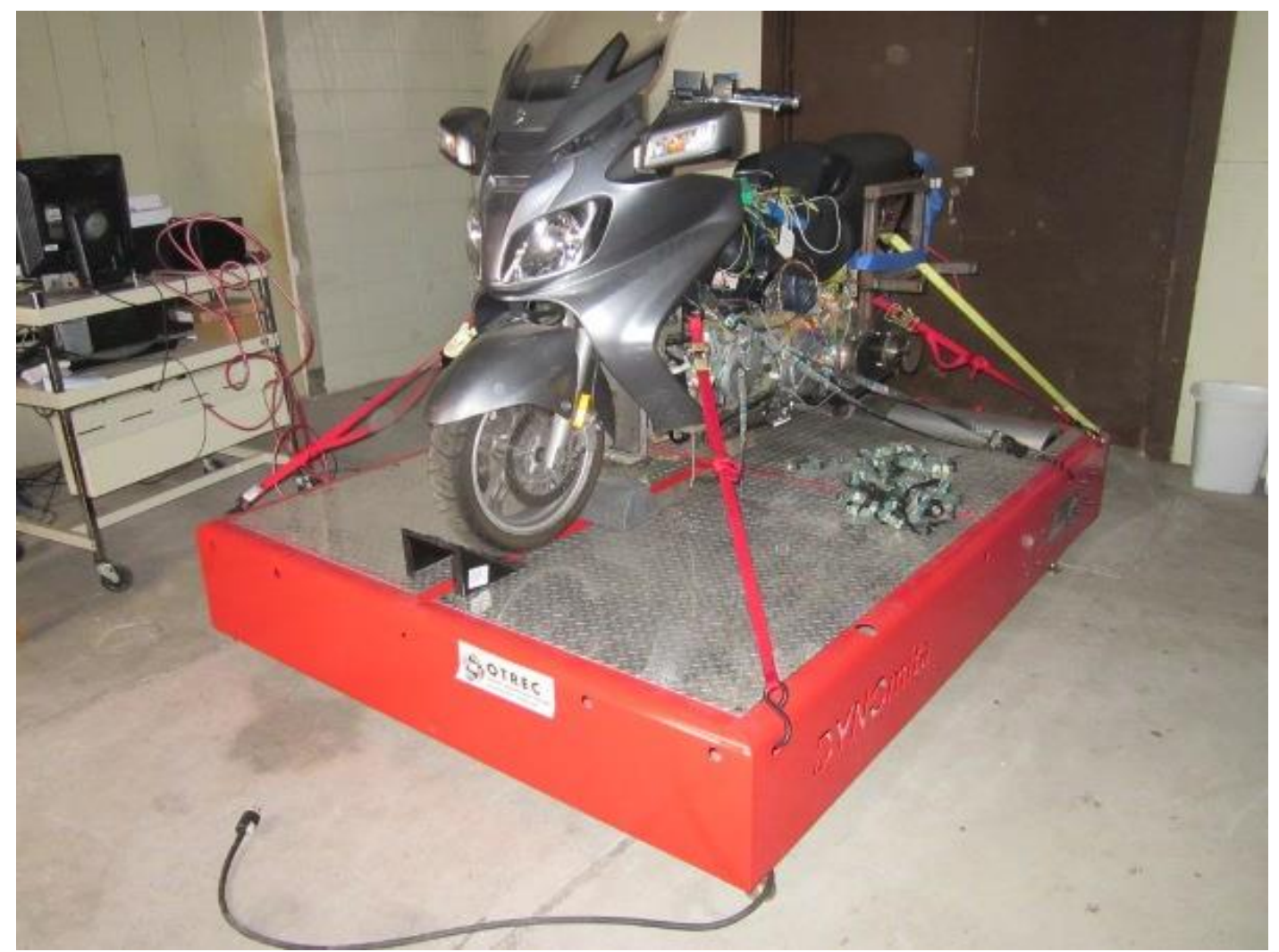

Figure 1.16 - The dynamometer with the Green Lite vehicle in the OIT dynamometer test room

The dynamometer was set up in the following configuration for all tests:

\section{Engine settings:}

- 11.2 compression ratio

- 2 cylinder

- $75.5 \mathrm{~mm}$ bore

- $71.3 \mathrm{~mm}$ stroke = displacement of $638.44 \mathrm{cc}$

\section{Inertia settings:}

- $\quad$ RPM-A $=0.0615 \mathrm{ft}-\mathrm{lb}-\mathrm{sec}^{2}$

- $\quad \mathrm{RPM}-\mathrm{B}=8.824 \mathrm{ft}-\mathrm{lb}-\mathrm{sec}^{2}$

- $\mathrm{RPM}-\mathrm{C}=0.192 \mathrm{ft}-\mathrm{lb}-\mathrm{sec}^{2}$

- $\mathrm{RPM}-\mathrm{b} / \mathrm{a}$ ratio $=1.000$

- $\quad \mathrm{RPM}-\mathrm{c} / \mathrm{b}$ ratio $=2.029$

- Calculate torque with: \#1 compensation on

\section{Vehicle settings:}

- Bike weight for simulation $=800 \mathrm{lbs}$. (assumed factory dry weight of $524 \mathrm{lbs}$ minus $24 \mathrm{lbs}$ of plastic, $150 \mathrm{lbs}$. of equipment and $150 \mathrm{lbs}$. of rider) 
- Coast down G's set for 0.07 at $55 \mathrm{mph}$.

- Tire diameter of 21.56 .

- Speedometer source of \#0 shaft rpm

- Acceleration source \#0 speedometer

- Pitch compensation $0 \%$

\section{Dynamometer specific settings:}

- Vehicle speed factor 21

- Drive ratio $=2.029$

- Roll diameter 16 inches

- $\quad$ RPM source $=\# 3$

- RPM-A, RPM-C, torque source \#0 DYNOmite ${ }^{\mathrm{TM}}$ board

Tests were run with an automatic simulated grade test, which uses the eddy current absorber when set in automatic mode. Simulation settings were:

- max hill grade $0 \%$

- $\quad$ min time between hills $=400$ seconds

- \# of hills per lap $=5$

- $\quad$ of laps this test $=4$

Recording rate was not used, and both the randomized hill grade and randomized time between hills were turned off so it would be over the 10-minute run times for tests. It was also set to offer the most resistance during starting acceleration and just a little bit at a given speed (what they have figured for drag while riding at a given speed).

The DYNO-MAX has a Road Load Simulation mode where vehicle speed is controlled based on the cumulative power applied during the test calculated against the vehicle drag and weight information input. In this mode there is an exponentially increasing load applied to the vehicle as it accelerates. Conversely, a coasting effect will be applied during deceleration. This is a convenient mode for engine management system mapping or diagnostic testing. The coast down G's values typical bike (touring) 800 pounds $=0.070$.

The RPM source was taken from the bike's number one signal (positive coil) wire through the Hall Effect sensor for the dyne. This gives bike rpm. The speed of the roller is detected with another Hall Effect sensor to get exact mph readings of the bike. The bike on-board speedometer was incorrect because of the modifications to the gear train.

\subsubsection{Vehicle Instrumentation}

Parameters of interest from the vehicle were fuel flow for integration of fuel consumption during a test run, charge flow for integration of electric energy consumption during a test run, vehicle speed, distance traveled, and time. 


\subsubsection{Fuel Consumption}

The fuel-flow sensor used is a Futurlec 2.0 to $30.0 \mathrm{~L} / \mathrm{hr}$ Diesel and Gasoline Flow Sensor. This flow meter was mounted directly in line with the gasoline feed to get an independent measure of fuel consumption. Specifications of this device are:

- Flow rate 2.0 - 30.0 liter/hr

- Digital output

- Fitting for 3/8" barb

- Suitable for both diesel and gasoline

- Open collector output

- Fluid temperature: 0 to $60 \mathrm{oC}$

- Fluid pressure: up to 85 psi

- Supply voltage: 2.4 - 26V

The sensor is shown in Figure 1.17.

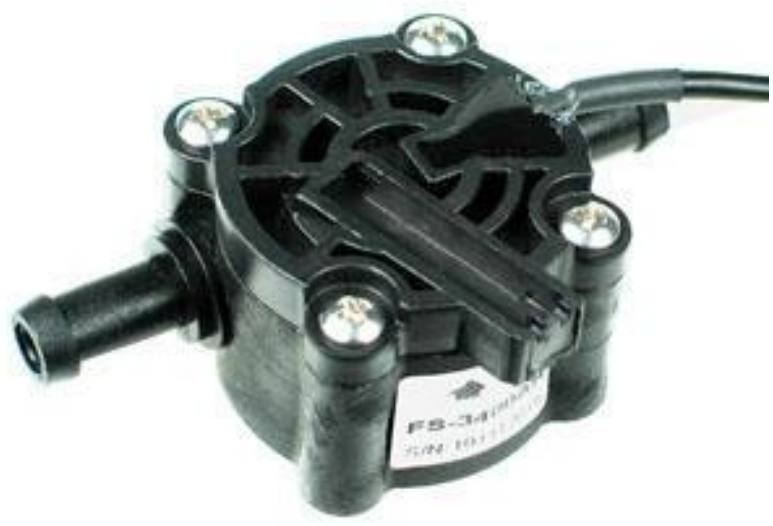

Figure 1.17 - Fuel-flow sensor used in the testing setup

The sensor was connected to a National Instruments data acquisition harness (described below) for counting of sensor pulses during a run.

Table 1.1 shows the calibration setting for the sensor.

Table 1.1: Futurlec flow meter pulse calibration

\begin{tabular}{l|l}
\hline Flow Rate(LPH) & Liters per Pulse \\
\hline 2.0 & 0.00038 \\
\hline 4.0 & 0.00050 \\
\hline 12.0 & 0.00050 \\
\hline 30.0 & 0.00050 \\
\hline
\end{tabular}

For each run, the pulses were counted and used to sum the final fuel consumption. 


\subsubsection{Electrical Power Consumption}

To measure electrical power consumption, an AcuAMP DCT200-10B-24-S

Hall Effect current transducer was placed around the positive power cable leading out of the battery bank. Specifications for this device are:

- 0-200A input

- 24V DC powered

- bi-polar +/- 0-10 VDC output

An image of the transducer is shown in Figure 1.18.

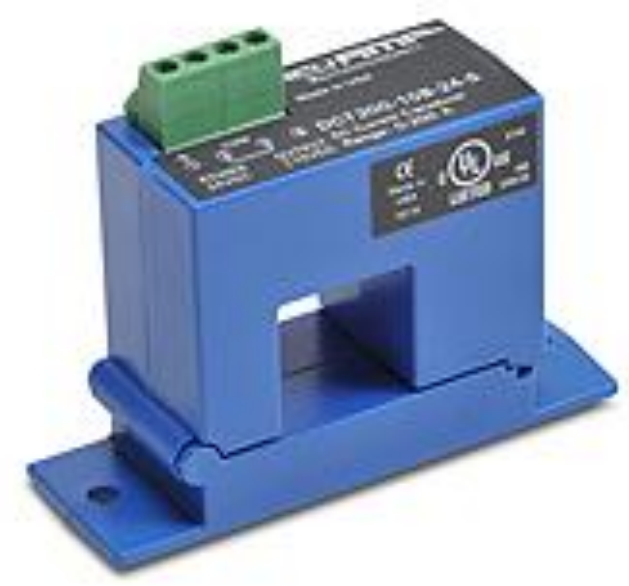

Figure 1.18 - AcuAMP DCT200 Hall Effect current transducer used for power consumption data acquisition

The -10 volt to 10 volt signal was sampled and integrated over time to accumulate the amp-hours consumed during any specific run.

\subsubsection{Data Acquisition}

To capture the data, a National Instruments USB 6009 PC DAQ Module was used to pick up the analog signal from the current transducer and the pulse from the fuel-flow meter. The National Instruments module is shown in Figure 1.19. 


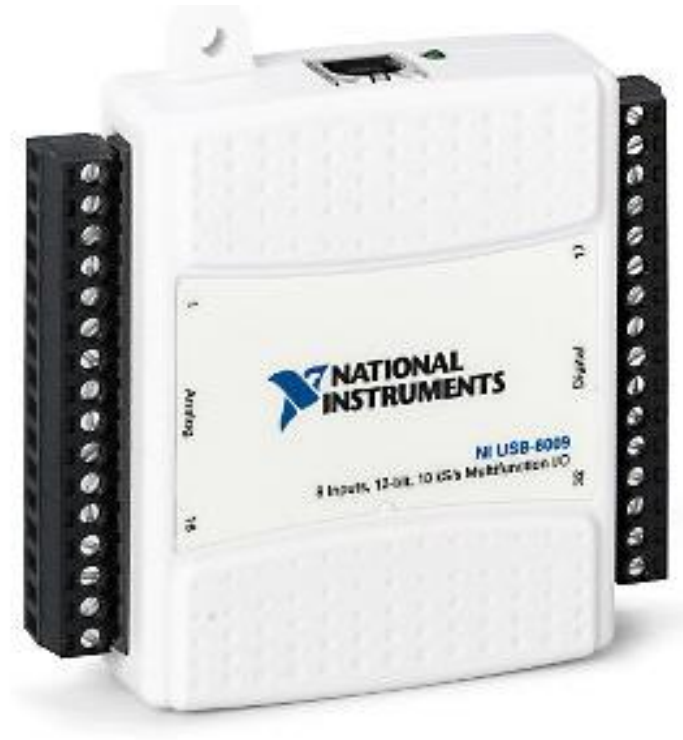

Figure 1.19 - NI USB 6009 PC DAQ Module

Vehicle runs were done at a steady state speed to avoid issues related to correlating vehicle speed over time to the data produced by the current transducer and flow meters.

Data acquisition was done with a standard desktop PC running LabView software. A program was developed for acquiring the data and performing initial data reduction tasks.

\subsection{EDUCATIONAL OBJECTIVES}

In addition to performing the testing of the Green Lite vehicle, in line with OIT's mission, the project was used to educate undergraduate students in vehicle technology, hybrid vehicle design and deployment, as well as vehicle software systems implementation and deployment. As a necessary part of any research project taken on at OIT, undergraduate involvement is integrated into the project in the form of student projects (Long, 2012), student assistants, and individual work as laboratory assignments or case studies. Objectives for this project were to engage students in:

- Vehicle test planning and test execution

- Creation of a data telemetry system for test drive data acquisition

- Creation of a remote vehicle access and control system

- Assistance in mechanical system testing involving dynamometer use

- Work on control algorithm and user interface implementation 


\subsection{TESTING METHODOLOGY}

\subsection{OVERVIEW}

Testing was primarily performed in the dynamometer laboratory with a few simple and abbreviated parking lot tests. No extended road tests were performed due to equipment failure in the early phases of electric drive system testing. The testing was done in three phases. First the internal combustion (IC) engine drive system was tested without the use of the electric drive system. Second, the electric drive system was tested with the IC engine idling. Third, the two systems were engaged to test hybrid operation.

\subsection{INTERNAL COMBUSTION DRIVE TESTING}

The IC drive system was tested at steady state speeds to capture mileage performance through 10 mph increments up through $70 \mathrm{mph}$. Steady state testing was done with the electric motor chain drive connected but not energized. It was acting only as a flywheel. Testing was done by bringing the bike up to testing speed, initiating a data acquisition run and holding the speed constant for five minutes. Dynamometer readings of RPM and horsepower (for the second set of tests) at the rear wheel were recorded. The miles-per-gallon indicator on the Burgman control panel was used to get a reading at the end of each run. The gage was reset at the beginning of a run and read at the end of the run. The flow meter was also used to capture fuel consumed for each run through the LabView data acquisition program.

\subsection{ELECTRIC DRIVE TESTING}

The electric drive system was also tested at steady state speeds to capture miles-per-watt-hour performance through $10 \mathrm{mph}$ increments up through $50 \mathrm{mph}$. Steady state testing was done with the IC engine in idle, a requirement imposed through the use of the dynamometer and its dependence on operation of the IC engine. As with the IC engine testing, this was done by bringing the bike up to testing speed, initiating a data acquisition run and holding the speed constant for five minutes. The LabView system was used to capture the amps used during the test runs.

\subsection{HYBRID DRIVE TESTING}

Hybrid mode testing was also done at steady state speeds where the percentage of electric power being utilized was also held at a steady state. The goal was to test different levels of electric power use in conjunction with the IC engine to gain a mileage curve based on different energy levels of support of the electric motor. In these tests, the vehicle was brought up to speed using the IC engine, then the electric throttle was adjusted while backing off of the gasoline throttle until the electric motor was held steady at the required amp rating while holding the steady miles per hour. Each run was done for five minutes. The LabView system was used to capture the amps and fuel consumption during each test run. 


\subsection{TESTING RESULTS}

\subsection{OVERVIEW}

All testing was performed in OIT's dynamometer lab. The IC drive system was completed with some issues being discovered in the construction of the drive chain in the power transfer system to the bike's rear wheel. The electric system testing was completed up through the 50-mph mark, with catastrophic failure occurring in the battery system halfway through the $50-\mathrm{mph}$, fiveminute interval. After an overhaul of the battery bank and replacement of the damaged cells, the hybrid tests were started. Once again, due to an insufficient battery-management procedure, the battery bank had a second, test-induced failure, which was, in fact, the third battery bank failure. At this point, the test project was out of funds and it was clear the system would not be stable without the purchase and integration of a battery-management system for concise control of the battery bank state of charge. The testing was terminated at this point.

\subsection{INTERNAL COMBUSTION RESULTS}

During the first sequence of tests, the first-stage electric motor drive chain was very tight. During the $70 \mathrm{mph}$ run the chain and bearing at the swing arm became so hot the test was aborted. The chain was found to have overheated enough to discolor it and freeze some links. To alleviate this problem, a better-quality motorcycle chain was installed rather than an industrial chain.

The second sequence of runs was done with a looser chain tension. Even with these changes the chain tended to overheat. The drive chains were running beyond their recommended speed, which was probably the cause of the chain overheating. During design it was thought the chains would have a shortened life but otherwise function adequately. However, the increased speed causes overheating problems. Running the cycle for extended periods at speed is likely not possible. Testing is feasible for the short-duration tests required in this investigation. A redesign is needed for longer-term testing. In light of the current system limitations, design of a threestage system with a high-speed timing belt stage would be a feasible solution.

During the second sequence of runs, the testing was suspended between speeds to allow the chain to cool. The chains indeed become hotter at higher speeds, validating suspicion of the chain-over-speed problem. This was enough of a problem that the $70 \mathrm{mph}$ test was shortened from five minutes to two.

Tables 3.1 and 3.2 show the testing results of both sequences. Figure 3.1 shows the data in graphical form. 
Table 3.1: Gasoline drive system testing results - Test 1

\begin{tabular}{c|c|c|c}
\hline MPH & Flow Meter Count & MPG & \% error \\
\hline 10 & 803 & 10.3 & 3.3 \\
\hline 20 & 727 & 22.8 & 3.3 \\
\hline 30 & 810 & 30.7 & 1.6 \\
\hline 40 & 1138 & 29.2 & 8.2 \\
\hline 50 & 1220 & 34.0 & 2.4 \\
\hline 60 & 1398 & 35.8 & 4.8 \\
\hline 70 & n/a & n/a & n/a \\
\hline
\end{tabular}

Table 3.2: Gasoline drive system testing results - Test 2

\begin{tabular}{c|c|c|c}
\hline MPH & Flow Meter Count & MPG & \% error \\
\hline 10 & 829 & 10.0 & 3.3 \\
\hline 20 & 823 & 22.1 & 3.3 \\
\hline 30 & 1240 & 30.3 & 1.6 \\
\hline 40 & 1191 & 26.8 & 8.2 \\
\hline 50 & 1329 & 34.8 & 2.4 \\
\hline 60 & 1398 & 37.5 & 4.8 \\
\hline 70 & $758^{*}$ & 30.7 & n/a \\
\hline
\end{tabular}

* Two-minute run. All other runs are five minutes.

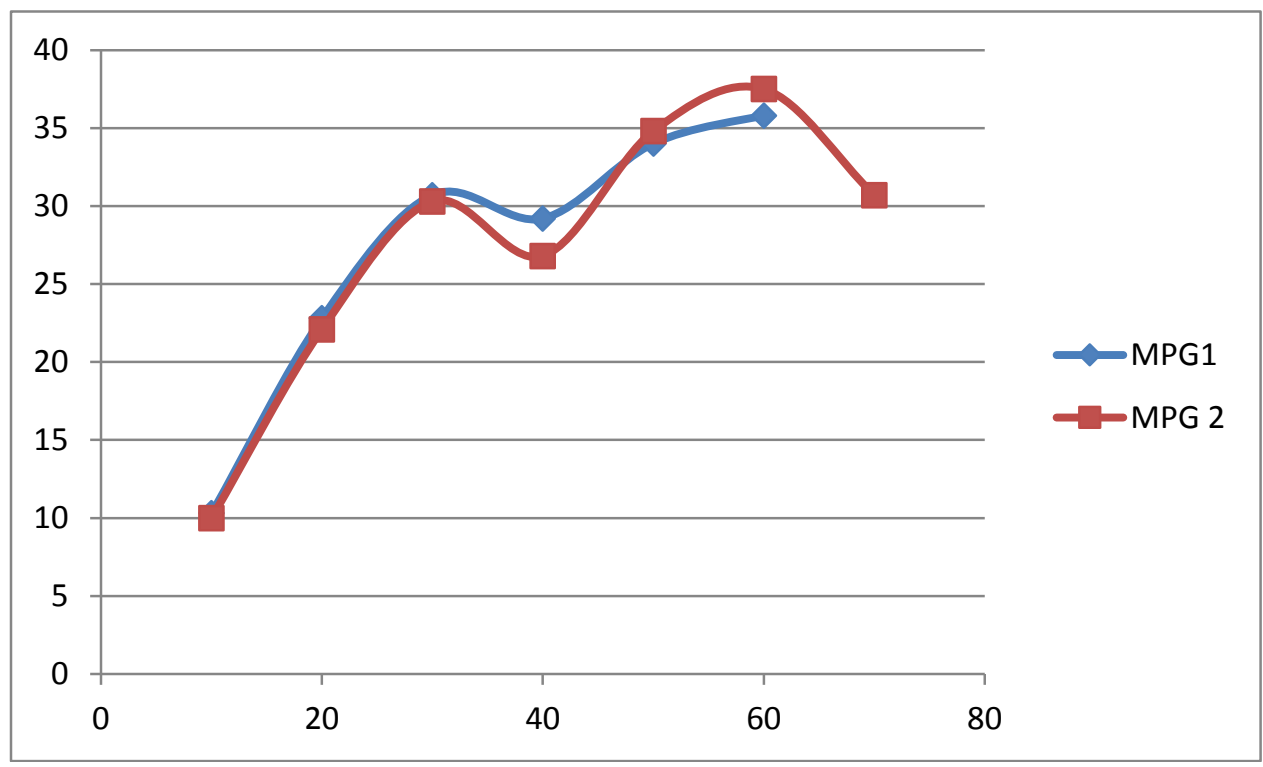

Figure $3.1-\mathrm{x}$ axis: $\mathrm{mph}$, $\mathrm{y}$ axis: $\mathrm{mpg}$

\subsection{ELECTRIC DRIVE RESULTS}

The electric drive testing went well for measuring of steady state 10, 20, 30 and $40 \mathrm{mph}$. On the run for $50 \mathrm{mph}$, the battery bank crashed, damaging 12 of the cells. Results of these tests are shown in Table 3.3 and a plot of $y$ - Miles vs. $x$ - Speed in $\mathrm{mph}$ is shown in Figure 3.2. Figure 
3.3 shows the energy consumption trend for the vehicle as the steady state speed increases, and Figure 3.4 shows the rate of electric energy consumption of speed vs. $\mathrm{kWh} / 100 \mathrm{mo}$. The range is based on exhausting the $80 \mathrm{Ah}$ battery bank to $25 \%$ of full charge.

Table 3.3: Electric drive system testing results

\begin{tabular}{c|c|c|c|c|c}
\hline MPH & Elapsed Time (s) & Ave Amps & Total Ah & Vehicle Range (Miles) & kWh/100mi \\
\hline 10 & 300 & 23 & 1.9 & 26 & 16.56 \\
\hline 20 & 300 & 40 & 3.4 & 30 & 14.4 \\
\hline 30 & 300 & 59 & 4.9 & 30 & 14.16 \\
\hline 40 & 300 & 99 & 8.2 & 24 & 17.82 \\
\hline 50 & 123 & 175 & 6.0 & 17 & 25.2 \\
\hline
\end{tabular}

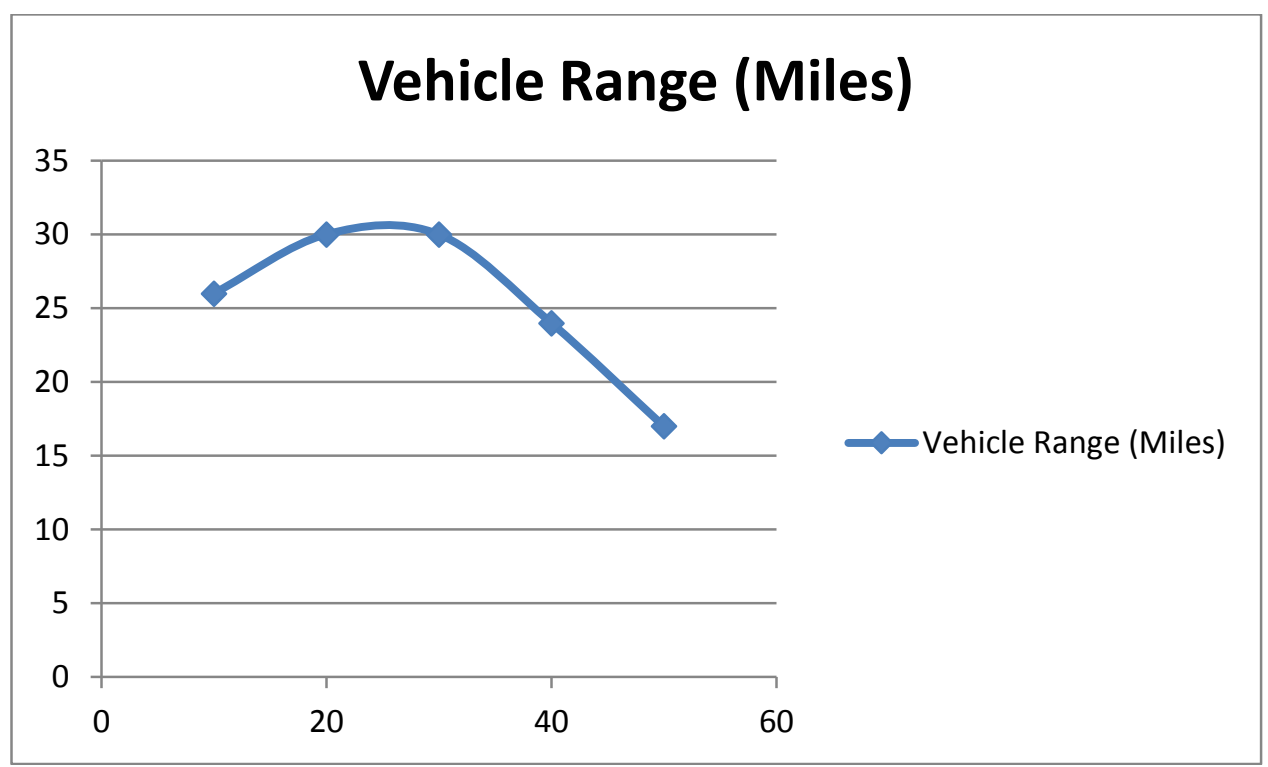

Figure 3.2 - Electric drive system range ( $\mathrm{x}$ - speed in mph vs. $\mathrm{y}$ - range in miles) 


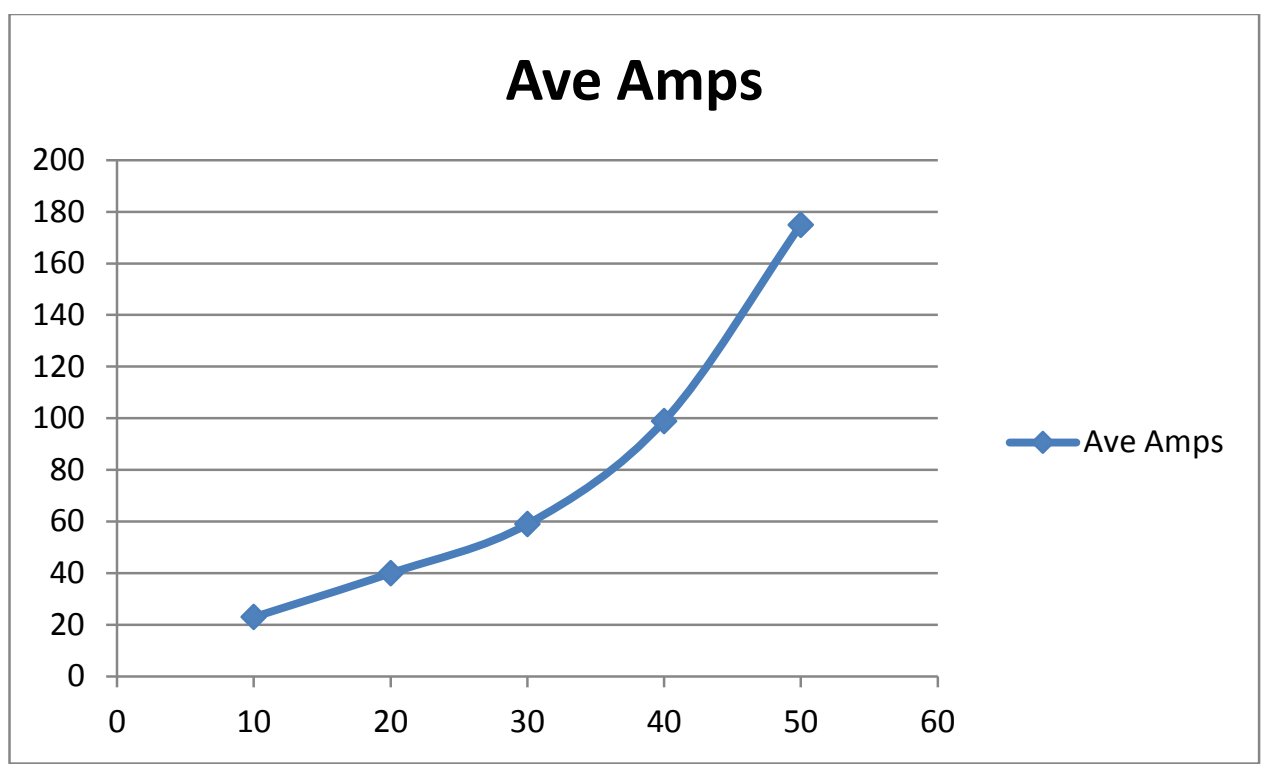

Figure 3.3 - Electric drive amp consumption ( $\mathrm{x}$ - speed in mph vs. $\mathrm{y}$ instantaneous amps)

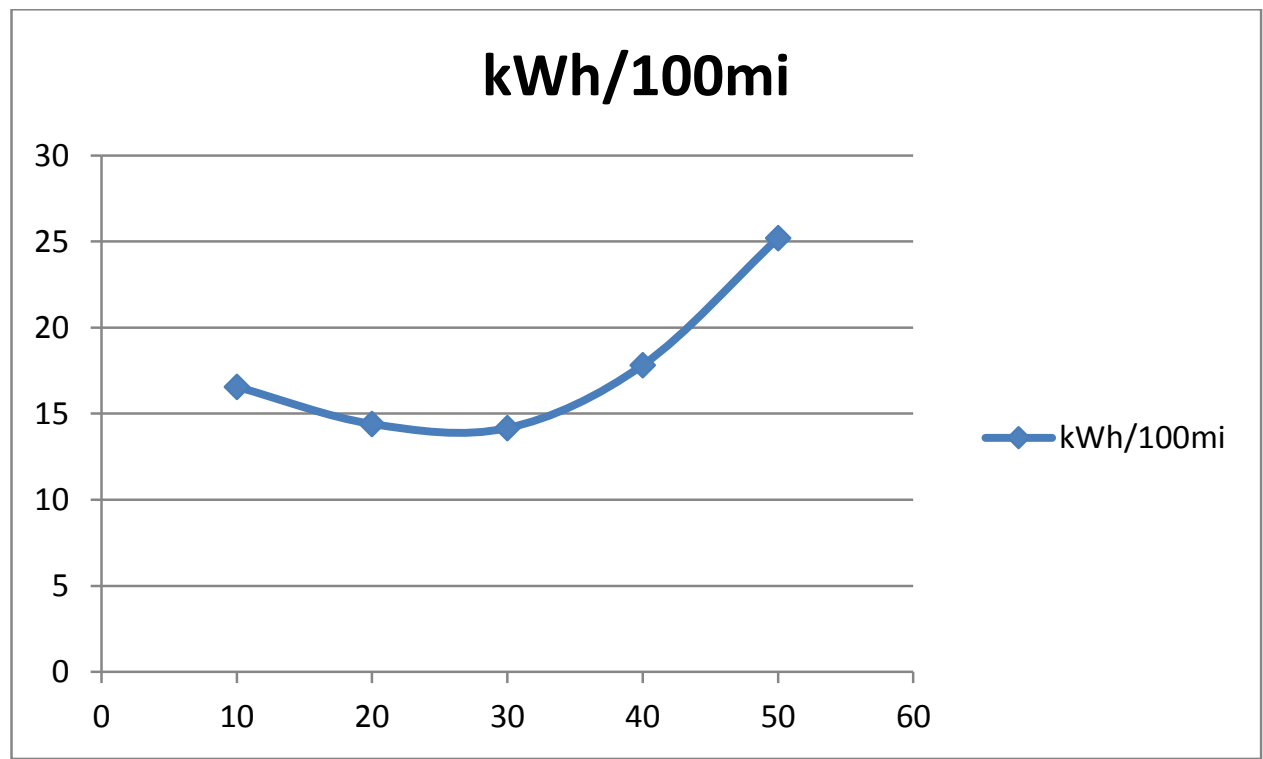

Figure 3.4 - Electric drive amp consumption ( $\mathrm{x}$ - speed in mph vs. $\mathrm{y}$ instantaneous amps)

In spite of the entire bank being fully charged prior to the runs and the runs themselves totaling 25 amp hours, the battery discharge caused catastrophic battery failure. By calculating for the individual runs, the battery bank should have been drained to $68 \%$. Despite this monitoring, several of the series strings of cells had been drawn down to the point of damage. Upon disassembly of the battery bank, a washer was recovered from one of the strings. The placement of the washer was such that it appeared to short out one of the cells in the string. This 
manufacturing anomaly is shown in Figure 3.5. The washer can be seen in the upper left battery where it was grounding the copper battery bus against the outside casing of the battery cell.

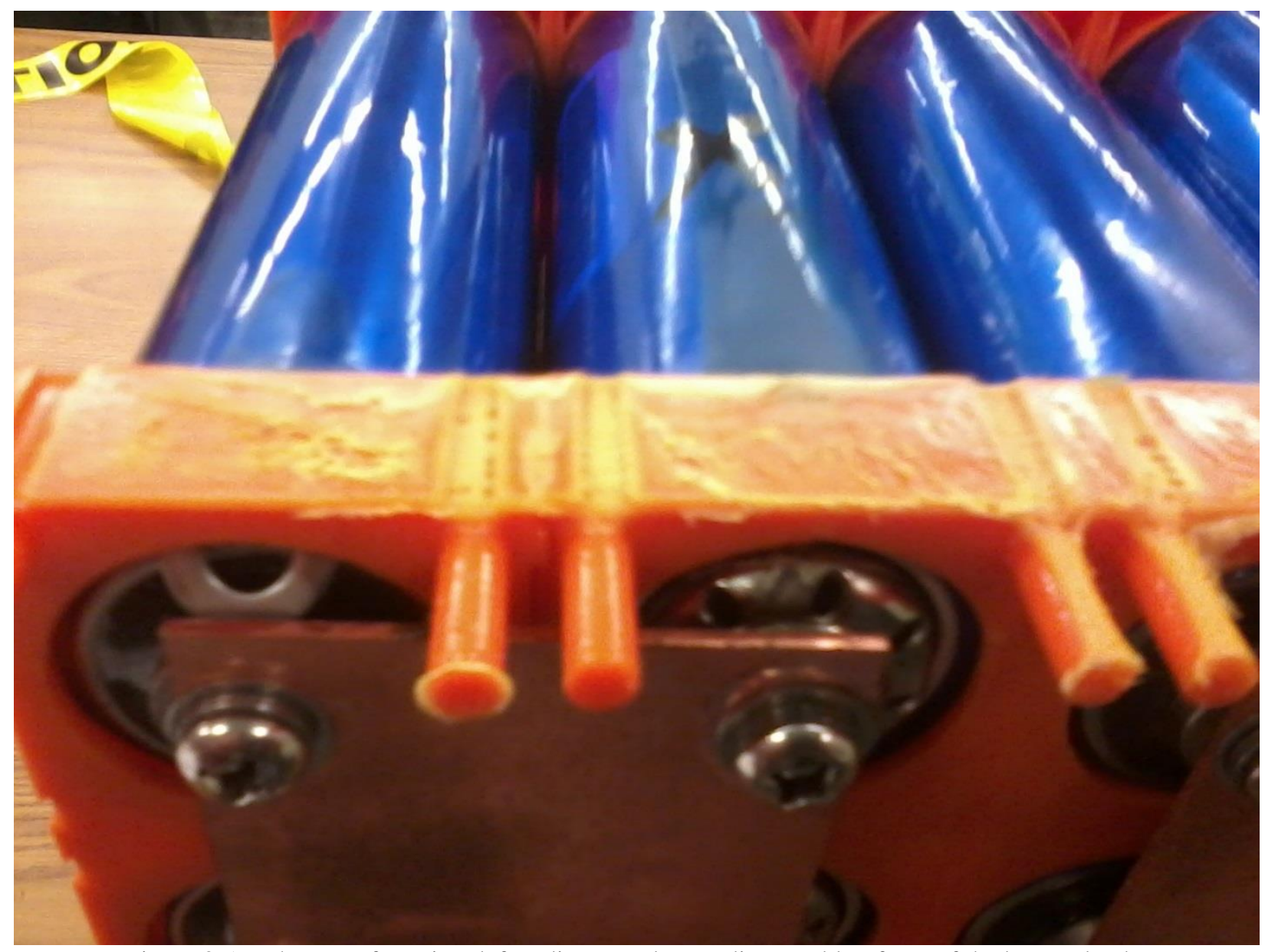

Figure 3.5 - The manufacturing defect discovered upon disassembly of one of the battery banks

When the batteries went off the low end of the charge curve, several cells ruptured their seals and leaked phosphate into the battery bank enclosures. This melted the plastic battery cell mounting brackets, making rebuilding the battery banks very difficult.

Each of the 22 parallel strings of cells were individually checked for charge capacity by using a power supply set at 3.7 volts, at 3 amps for at least eight hours. The cells were then checked for charge voltage. The strings capable of charging back to a nominal voltage of 3.2 volts were considered ok and retained in the battery bank. In total, three strings of cells were replaced with new cells. Once the battery banks were rebuilt, each parallel string of cells was individually charged with the power supply to the nominal voltage. The goal was to get the cells back to a steady state of charge.

Once all parallel strings were at the same nominal voltage (3.2 volts), the entire battery bank was put on the Quick Charge system to bring the bank up to full charge. After 1.5 hours, the battery banks overcharged and three more parallel strings blew their seals, resulting the damaging of 
another three strings of batteries. The battery banks were once again tested for permanent dead cells, new cells were purchased, and the battery banks were rebuilt.

At this point, it was determined the battery bank cell groups were too out of balance to use the Quick Charge system, so the entire battery bank was charged using the slow method of individually charging parallel strings. The main issue with this method is there was no way to know the state of charge when beginning the power supply charge cycle, resulting in uncertainty about the charge state of the overall battery bank. We decided to move forward and attempt to obtain test results from the vehicle running in hybrid mode.

\subsection{HYBRID DRIVE RESULTS}

With the batteries seemingly fully charged, the hybrid drive operational tests were undertaken. The goal was to measure steady state mileage for $20 \mathrm{mph}, 20 \mathrm{amp}$ draw, $30 \mathrm{mph}, 20 \mathrm{amp}$ draw, up through $70 \mathrm{mph}, 200 \mathrm{amp}$ draw. This was to be repeated for $30 \mathrm{amp}, 40 \mathrm{amp}, 50 \mathrm{amp}, 60$ amp, and $70 \mathrm{amp}$, at each level of mph draw. Each test was to be done at the steady state for each different pair of mph-amp parameters. To keep close tabs on the batteries' actual draw down, the SOC Head Unit was used to double check the Hall Effect current transducer results. The system was to only be drawn down a maximum of 50\%, leaving a good margin for the undermined state of battery charge. The test was performed successfully for $20 \mathrm{mph}$ with a $20 \mathrm{amp}$ draw and 30 mph with a 20 amp draw. During the $40 \mathrm{mph}-20$ amp draw test, the battery bank once again crashed. Postmortem analysis of the battery bank confirmed destruction of another four parallel strings of eight batteries. At this point, the project budget was depleted and testing had to be terminated. Table 3.4 shows results of the hybrid test.

Table 3.4: Hybrid drive system testing results -20 amps

\begin{tabular}{c|c|c}
\hline MPH & Electric Range (miles) & MPG \\
\hline 20 & 59 & 25 \\
\hline 30 & 87 & 21 \\
\hline 40 & 118 & 1 \\
\hline
\end{tabular}

The boost in miles range for the battery system in hybrid mode vs. electric-only mode is good; however, the mpg as compared to the IC-engine only tests shows anomalies. The test needs to be run again to verify the mpg results. 


\subsection{ANALYSIS}

\subsection{OVERVIEW}

The complete test cycle was not possible because of issues encountered in the battery system; however, the testing performed was extensive enough to validate the operation and integrity of the different drive systems and their integration. During the course of testing, several small issues in system construction were uncovered and corrected. This included small items such as chain-to-frame interference, wire routing, chassis grounding, and high-speed mechanical system interference. From this course of testing, some key modifications were discovered that need to be implemented for the vehicle to be fully road tested.

Although initial testing of the gasoline drive system shows results lower than the stock Burgman mileage, early results from the electric range of the hybrid drive operation show a dramatic increase over electric-only drive range. Better instrumentation for the fuel-flow meter is required to get a fully accurate measure of the fuel mileage. The consistent poor mileage readings combined with results from the final run bring the low-cost Futurlec fuel-flow meter output into question.

\subsection{INTERNAL COMBUSTION}

Internal combustion (IC) drive system testing shows initial mileage lower than the factory reported mileage of $45 \mathrm{mpg}$ (Cope, 2013) for the Burgman 650. The highest mileage reported in the test runs of the Green Lite prototype vehicle is that of the $60 \mathrm{mph}$ run, registering at 37.5 mpg. It is not surprising that the IC system has a lower mileage because of the extra mechanics involved in the overall drive system. The fuel-flow meter used for independent verification of fuel consumption is also suspect as a potential problem in the test sequences. Although it had mostly consistent data, on occasion it would report results abnormally high, causing some test runs to be rejected as outliers. The overheating of the drive chain also hints at an area of design inefficiency and possible drain on mileage.

Although the mpg of the tests was low compared to a stock vehicle, they were not out of expected range given the modifications made to the drive system. Expectation is the IC engine drive combined with the electric drive for full hybrid operation will increase mileage considerably.

\subsection{ELECTRIC DRIVE}

Electric motor drive system testing shows more promising results. The highest level of efficiency is reported at roughly $25 \mathrm{mph}$ with an energy consumption of $14.2 \mathrm{kWh} / 100 \mathrm{mi}$. The energy consumption for the $50-\mathrm{mph}$ run is $25.5 \mathrm{kWh} / 100 \mathrm{mi}$. These results are quite good for a twopassenger vehicle. For a comparison to a current high vehicle, designed to be only electric, the 2013 Smart Car electric vehicle gets a combined city/highway energy consumption of 32 kWh/100mi (Energy, 2013). The Green Lite prototype configuration has roughly 50\% higher $\mathrm{kWh}$ mileage at $40 \mathrm{mph}$ if the Smart Car mileage is assumed to be captured at an average speed of $40 \mathrm{mph}$ in mileage tests. 


\subsection{HYBRID DRIVE}

Although the hybrid-mode tests were inconclusive due to battery bank failure and fuel-flow meter anomalies, results did show the combined use of the IC engine and electric motor enhanced the range of the vehicle dramatically. In the electric-only test, at $20 \mathrm{amps}$, the range of the vehicle came out to 26 miles at a speed of $10 \mathrm{mph}$. In hybrid mode, the IC-engine assist increased the range from 30 miles to 87 miles. As an electric-motor assist, the combination is quite effective in increasing vehicle range.

From a fuel-consumption perspective, the results are dismal but the meter for measuring fuel flow is suspect in the results it produced. To get a good measure of overall fuel efficiency, the hybrid tests need to be completed with a higher-grade, fuel-flow meter in the fuel line. The tests for hybrid-mode fuel consumption are inconclusive.

\subsection{EDUCATIONAL OUTCOME}

The project proved to be a very beneficial educational opportunity for OIT. Project issues and technical challenges were used in several case studies in the Renewable Energy Engineering program, the Embedded Systems Engineering program, and the Software Engineering program. Students had the opportunity to gain hands-on experience in working directly with the engineering, specification and prototype construction in all phases of the project. Roughly 30 students were involved over the life of the project. Several side projects were generated from the Green Lite prototype testing grant cycle:

- Testing and Remote Telemetry System - This project involved four software engineering students in a three-term effort to create a data acquisition and remote data telemetry system for use on the vehicle during road tests. This was integrated into a junior-level design and construction course.

- Remote Vehicle Control - This project involved four software engineering students in a three-term effort to build a wireless, iPad application that would allow the vehicle to be remotely controlled and status monitored over a wireless network connection. This project was integrated into a junior-level design and construction course.

- Vehicle to Grid System Design - This was a problem presented to a senior-level renewable energy design course. The project involved producing a hardware design to allow the battery bank from a vehicle to be used as peak-use storage for a utility company. Ten students looked at the vehicle and grid-based charger side of the system to produce a proposed hardware design for both the grid-based charge and the vehicle-based charging. A monetary incentive program was also proposed to give vehicle owners incentive to use their vehicles as temporary grid-based storage.

In addition to the coursework project integration, several students were employed under the grant contract throughout the course of the grant. This involved management and running of the dynamometer tests, implementation of the embedded control system and control algorithm, implementation of the embedded controller user interface, and work on data acquisition and sensor circuits. 


\subsection{CONCLUSION}

The Green Lite prototype project was not able to prove the ultimate efficiency of the Green Lite next-generation hybrid vehicle prototype. Problems with the battery system and management of the LiFePO4 battery bank caused unexpected time, effort and expense to creep into the project scope. Ultimately, battery failure and depletion of the project budget brought the testing to a premature end.

The prototype design shows promise as an electric vehicle. As compared to current two-person electric vehicles, the $\mathrm{kWh} / 100 \mathrm{mi}$ performance is better than popular systems. The main issue of the Green Lite vehicle as an electric vehicle is driving range. With the IC engine brought in as a parallel hybrid drive the electric system's range is extended, making the Green Lite platform a good commute vehicle favoring mainly the electric system as the primary source of power. Performance of the IC engine drive is undetermined, and further testing of the IC engine needs to be done to characterize full hybrid operation.

The following recommendations result in the initial testing of the Green Lite second-generation prototype:

1. Drive train modification - The current system has drive chains for transfer of energy from the electric motor to the rear wheel. These chains overheated during the higher speed tests, forcing a limited time the vehicle could be run. A five-minute run produced intolerable chain heat. This portion of the drive system needs to be redesigned with a high-speed timing belt. It is believed that a belt-based solution would not have the heat issues present in the normal application of a drive chain.

2. Integration of a full battery-management system - The lack of a battery-management system in conjunction with the volatile LeFePO4 battery chemistry proved to be the Achilles' heel of the project. Although the battery cells are well balanced when new, a simple error in manufacture or charging can cause the cell state of charge to be different. This causes issues when attempting to charge an entire battery bank as a single unit. An integrated battery-management system would alleviate issues of cell charge by managing smaller units of the overall battery bank.

3. Replacing the fuel-flow meter with a higher-quality unit - The flow meter used in testing mpg of the vehicle test runs had erratic behavior. This unit was an order of magnitude cheaper than the next level of meter. Reliable mileage numbers in the test phases of vehicle development will depend on a good device for data acquisition.

4. Further testing of the hybrid drive behavior - Due to equipment failure, the testing of the hybrid drive performance is inconclusive. To fully characterize the hybrid drive function, the entire suite of hybrid drive tests should be performed.

5. Adaptation of a later model vehicle - Due to the highly engineered nature of vehicles such as the Suzuki Bergman, modification to the vehicle and drive structure is extremely difficult. In the Bergman scooter product line, each new generation had an entirely new drive structure. For the hybrid modification to be applied to subsequent model years, each new year would require an engineering effort starting from reverse engineering of the new drive system. As the design of these vehicles become more fuel efficient, the 
modification of any given platform becomes increasingly difficult. Commercialization of a retrofit effort such as this needs a good supply of original vehicles to avoid continuous re-engineering of the hybridization solution. 


\subsection{REFERENCES}

Cope, B. (2013, April 28). 2013 Suzuki Burgman 650 Executive ABS review. Retrieved June 5, 2013, from Road Tests: http://www.visordown.com/road-tests-first-rides/2013-suzukiburgman-650-executive-abs-review/22676.html

Energy, U. D. (2013, 6 10). Electriv Vehicles: Compare side by side. Retrieved 7 5, 2013, from Fuel Economy.gov: http://www.fueleconomy.gov/feg/evsbs.shtml

Long, J. N. (2012). Integrating Electric Vehicles into Software Engineering Project Based Education. ASEE Annual Conference and Exposition, 2012 ASEE Conference and Exposition.

Long, J., Currin, H., \& Wang, X. (2012). Green Lite Hybrid Drive Commercialization Grant Final Report. Portland: Oregon BEST.

Xin Wang, Ph. D. (2012). Robust State Dependent Control of Discrete Time Nonlinear Systems with Random Actuator Failures. American Society of Mechanical Engineers, 2012 ASME Dynamical Systems and Control Conference. 



\section{GOTREC \\ AND EDUCATION CONSORTIUM}

P.O. Box 751

Portland, OR 97207

OTREC is dedicated to stimulating and conducting collaborative multi-disciplinary research on multi-modal surface transportation issues, educating a diverse array of current practitioners and future leaders in the transportation field, and encouraging implementation of relevant research results. 